\title{
Manganese transport by Streptococcus sanguinis in acidic conditions and its impact on growth in vitro and in vivo
}

\author{
Running title: Manganese and acid in S. sanguinis
}

Tanya Puccio ${ }^{1}$, Alexander C. Schultz ${ }^{2}$, Claudia A. Lizarraga ${ }^{2}$, Ashley S. Bryant ${ }^{2}$, David J. Culp ${ }^{2}$, Robert A. Burne ${ }^{2}$, Todd Kitten ${ }^{1 *}$

${ }^{1}$ Philips Institute for Oral Health Research, Virginia Commonwealth University School of Dentistry, Richmond, Virginia

${ }^{2}$ Department of Oral Biology, University of Florida College of Dentistry, Gainesville, Florida

*Corresponding author:

Todd Kitten_tkitten@vcu.edu 804-628-7010

\section{ORCID iD:}

Tanya Puccio: 0000-0002-0223-4885

David J. Culp: 0000-0002-2124-6347

Robert A. Burne: 0000-0002-4234-0316

Todd Kitten: 0000-0001-6097-7583

\section{Data Availability Statement:}

The RNA-seq data discussed in this publication have been deposited in NCBI's Gene Expression Omnibus (Edgar et al., 2002) and are accessible through GEO Series accession number GSE174672. The remaining data that support the findings of this study are available from the corresponding author upon reasonable request (Puccio et al., 2021c).

\section{Funding Statement:}

This work was supported by the National Institutes of Health: award no. R01 AI114926 to TK from the National Institute of Allergy and Infectious Diseases; awards no. R01 DE025832 to RAB and no. F31 DE028468 to TP from the National Institute of Dental and Craniofacial Research. The content is solely the responsibility of the authors and does not necessarily represent the official views of the National Institutes of Health.

\section{Conflict of Interest Disclosure:}

All authors have no competing interests to declare.

\section{Ethics Approval Statement:}

The University of Florida IACUC approved all animal procedures (IACUC Study \#201810470), following the US Public Health Service's "Policy on Humane Care and Use of Laboratory Animals" and "Guide for the Care and Use of Laboratory Animals." 


\section{Summary:}

Streptococcus sanguinis is an oral commensal and an etiological agent of infective endocarditis. Previous studies have identified the SsaACB manganese transporter as essential for endocarditis virulence; however, the significance of SsaACB in the oral environment has never been examined. Here we report that a $\triangle s s a A C B$ mutant of strain SK36 exhibits reduced growth and manganese uptake under acidic conditions. Further studies revealed that these deficits resulted from the decreased activity of TmpA, shown in the accompanying paper to function as a ZIPfamily manganese transporter. Transcriptomic analysis of fermentor-grown cultures of SK36 WT and $\triangle s s a A C B$ strains identified $\mathrm{pH}$-dependent changes related to carbon catabolite repression in both strains, though their magnitude was generally greater in the mutant. In strain VMC66, which possesses a MntH transporter, loss of SsaACB did not significantly alter growth or cellular manganese levels under the same conditions. Interestingly, there were only modest differences between SK36 and its $\triangle s s a A C B$ mutant in competition with Streptococcus mutans in vitro and in a murine oral colonization model. Our results suggest that the heterogeneity of the oral environment may provide a rationale for the variety of manganese transporters found in $S$. sanguinis and point to strategies for enhancing the safety of oral probiotics.

\section{Keywords:}

18 Dental caries; carbon catabolite repression; NRAMP-family protein; ATP-binding cassette; ZIPfamily protein

\section{Introduction}

The oral cavity is a complex environment with dynamic microbial communities, fluctuating metabolite availability, and diverse habitats (Lamont et al., 2018, Aas et al., 2005, Marsh et al., 2016, Kolenbrander, 2011, Jakubovics, 2015, Kolenbrander et al., 2010, Chen et al., 2010). Resident microorganisms must compete for space and nutrients within each of these habitats, including the dental biofilm known as plaque. Some species, such as Streptococcus mutans, utilize acid production to carve out their own niche by lowering the $\mathrm{pH}$ of the local environment. This allows competition with other less aciduric (acid-tolerant) species but also results in demineralization of the tooth enamel, or dental caries (Gross et al., 2012, Nascimento et al., 2009, Moye et al., 2014).

One of the species $S$. mutans competes with is Streptococcus sanguinis. While $S$. sanguinis is acidogenic (acid-producing), it lacks the aciduricity of $S$. mutans (Bender et al., 1986, DiazGarrido et al., 2020, Sasaki et al., 2018, Svensater et al., 1997). Conversely, S. sanguinis possesses the ability to produce (Kreth et al., 2008, Garcia-Mendoza et al., 1993) and survive in (Xu et al., 2014) large quantities of hydrogen peroxide $\left(\mathrm{H}_{2} \mathrm{O}_{2}\right)$, which is thought to enhance its ability to compete against $S$. mutans, which does not produce $\mathrm{H}_{2} \mathrm{O}_{2}$ (Kreth et al., 2005). Thus, $S$. sanguinis is typically found in much greater abundance at healthy oral sites while $S$. mutans

37 predominates in carious lesions (Giacaman et al., 2015, Belda-Ferre et al., 2012, Gross et al., 38 2012).

Oral bacteria possess a variety of mechanisms for tolerating acid stress (Papadimitriou et al., 40 2016, Guan \& Liu, 2020, Liu et al., 2015, Quivey et al., 2001, Cotter \& Hill, 2003). The $S$. 41 sanguinis genome ( $\mathrm{Xu}$ et al., 2007) encodes multiple systems that are predicted to play a role: $42 \mathrm{~F}_{0} \mathrm{~F}_{1}$-ATPases (Kuhnert \& Quivey, 2003); an arginine deiminase system (Burne et al., 1989, 
Curran et al., 1995, Floderus et al., 1990); various chaperones and proteases (Shabayek \& Spellerberg, 2017, Lemos et al., 2001, Lemos \& Burne, 2002); and superoxide dismutase (Kim et al., 2005, Wen \& Burne, 2004, Crump et al., 2014). S. sanguinis also appears to possess an acid tolerance response (ATR), whereby brief exposure to sub-lethal acid levels protects against a lethal drop in $\mathrm{pH}$ (Cotter \& Hill, 2003), although it is less effective than that in the related species Streptococcus gordonii (Cheng et al., 2018). Each of these systems likely contributes to the survival of $S$. sanguinis in acidic environments.

Manganese (Mn) has recently been implicated in acid stress tolerance in Streptococcus agalactiae (Shabayek et al., 2016) and S. mutans (Kajfasz et al., 2020). In both species, loss of a natural resistance-associated macrophage protein (NRAMP) family manganese transporter, $\mathrm{MntH}$, led to a reduction in growth in acidic conditions. In S. mutans, the loss of the lipoprotein component of the $\mathrm{ABC}$ manganese transporter, SloC, did not impact growth in acidic media unless the $s l o C$ mutation was combined with the $m n t H$ mutation (Kajfasz et al., 2020). Similarly, it was previously determined that the fimCBA operon was not important for acid tolerance in Streptococcus parasanguinis (Chen et al., 2013), which also possesses a $m n t H$ gene. Manganese transport has also been examined in $S$. sanguinis, which possesses an analogous $\mathrm{ABC}$ transport system encoded by the $s s a A C B$ operon but not a $m n t H$ gene in most strains. These studies have established the importance of manganese not for acid tolerance, but for virulence in relation to the disease infective endocarditis (Crump et al., 2014, Baker et al., 2019). S. sanguinis is a frequent cause of this serious illness, which exhibits a 12-30\% mortality rate (Bor et al., 2013, Cahill et al., 2017, Jamil et al., 2019, Wilson et al., 2021) and for which the only form of prevention-antibiotic prophylaxis-is controversial. This has led to the investigation of SsaB, the lipoprotein component of the $\mathrm{ABC}$ manganese transport system, as a target for endocarditis prevention. Given the association of $S$. sanguinis with health in the oral cavity, targeting of SsaB would be of greater value if this does not compromise oral competitiveness.

Here we report for the first time the growth of a naturally MntH-deficient streptococcal strain, $S$. sanguinis SK36, under reduced-pH conditions and for the first time in any bacterium, the effect of reduced $\mathrm{pH}$ on manganese transport by a newly described ZIP family transporter. We then assess the growth of a MntH-encoding strain of S. sanguinis, VMC66, in reduced-pH conditions. Finally, we report the effect of deleting the $\mathrm{ABC}$ manganese transporter on the competitive fitness of S. sanguinis against $S$. mutans in vitro and in vivo.

\section{Results}

\section{Growth of S. sanguinis at reduced $\mathbf{p H}$}

76 As a first step in determining whether manganese transport is important for growth at reduced $\mathrm{pH}$ in S. sanguinis, we employed a mutant of SK36 in which the ABC manganese transporter SsaACB has been deleted (Baker et al., 2019). We assessed the growth of wild-type (WT) SK36 and its $\triangle$ ssaACB single transport-system mutant in brain heart infusion (BHI) broth at its unadjusted $\mathrm{pH}(\sim 7.3)$ and under increasingly acidic conditions (Figure 1A). We have recently demonstrated that this mutant grows significantly less well than WT in a low-manganese medium, serum, in $6 \% \mathrm{O}_{2}$ but indistinguishably in $1 \% \mathrm{O}_{2}$ (Puccio et al., 2021a). To rule out 83 oxidative stress as a confounding factor, cells were grown in microaerobic conditions $\left(1 \% \mathrm{O}_{2}\right)$. 84 At $\mathrm{pH} 7.3$, the culture densities of the two strains were not significantly different from each 85 other. When the $\mathrm{pH}$ was lowered to 6.4 and 6.3 , the final density of the WT culture was not 
progressively decreased. The final density of both cultures at $\mathrm{pH} 6.2$ was significantly less than at $\mathrm{pH} 7.3$, although the difference was much greater for the $\triangle s s a A C B$ mutant than for WT.

Although we suspected that the growth arrest of the $\triangle s s a A C B$ mutant at $\mathrm{pH} 6.2$ was due to lower manganese levels in this strain (Murgas et al., 2020), we wanted to test this hypothesis directly. We previously measured the concentration of manganese in BHI from the same supplier as that used in the present study by inductively coupled plasma mass spectrometry (ICP-MS) and found that it averaged $0.36 \mu \mathrm{M}$ (Murgas et al., 2020). We added exogenous $\mathrm{Mn}^{2+}$ to $\mathrm{pH} 6.2$ cultures of the $\triangle s s a A C B$ mutant and found that the addition of $10 \mu \mathrm{M} \mathrm{Mn}{ }^{2+}$ was sufficient to rescue the growth (Figure 1B), suggesting that the reduced manganese levels found in this mutant (Murgas et al., 2020) were contributing to the reduced ability to tolerate low $\mathrm{pH}$ conditions.

\section{7}

98

99

100

101

102

103

104

105

106

107

108

109

110

\section{Contribution of secondary manganese transporters to acid tolerance}

The success of the manganese rescue experiment shown in Figure 1B suggests the existence of an additional mechanism for manganese uptake, albeit one with lower affinity than the SsaACB transporter. In the accompanying manuscript (Puccio et al., 2021a), we report the identification and characterization of a ZIP family protein, TmpA, as a secondary manganese transporter present in at least 64 S. sanguinis strains whose sequences are available in the GenBank wholegenome shotgun contigs database. Additionally, we noted the presence of a gene encoding a third manganese transporter from the NRAMP family (Nevo \& Nelson, 2006), MntH, in eight of these strains, one of which was VMC66. We hypothesized that each of the three S. sanguinis manganese transporters are at least partly redundant but may have optimal activity under differing conditions. In $S$. agalactiae, $\mathrm{MntH}$ functions best at acidic $\mathrm{pH}$ and its gene is expressed highly at pH 5 (Shabayek et al., 2016). The ZIP-family protein in Escherichia coli was found to function best near neutral $\mathrm{pH}$ (Taudte \& Grass, 2010) and we have yet to determine a condition where the tmpA gene in S. sanguinis is differentially expressed (Puccio et al., 2021a).

To determine whether TmpA contributes to the growth of SK36 WT or $\triangle s s a A C B$ mutant cells at normal or reduced $\mathrm{pH}$, we assessed the growth of $\triangle$ tmpA mutants in both backgrounds in BHI $\mathrm{pH} 7.3$ and 6.2 in an atmosphere of $1 \% \mathrm{O}_{2}$ (Figure 2A). Growth of the $\triangle$ tmpA mutant was not affected at either $\mathrm{pH}$, indicating that $\mathrm{SsaACB}$ transports sufficient manganese at $\mathrm{pH} 6.2$ to maintain growth. The double $\triangle s s a A C B \triangle t m p A$ mutant grew poorly at both $\mathrm{pH} 7.3$ and 6.2 and its growth was not significantly different from that of its $\triangle s s a A C B$ parent at $\mathrm{pH} 6.2$.

In the VMC66 background, we generated mutants deleted for each of the transporters: $\triangle t m p A$, $\triangle m n t H$, and $\triangle s s a A C B$, as well as double mutants lacking SsaACB and one of the secondary transporters: $\triangle s s a A C B \triangle t m p A$, and $\triangle s s a A C B \triangle m n t H$. We then assessed their growth in BHI $\mathrm{pH}$ 7.3 and $\mathrm{pH} 6.2$ at $1 \% \mathrm{O}_{2}$ (Figure 2B). All strains grew identically at $\mathrm{pH} 7.3$ but growth of the $\triangle s s a A C B \Delta m n t H$ strain was dramatically reduced at $\mathrm{pH} 6.2$.

We also wanted to assess whether the decreased growth of the SK36 $\triangle$ ssaACB $\triangle t m p A$ mutant and the VMC66 $\triangle s s a A C B \triangle m n t H$ mutant observed in Figure 2A-B was primarily due to decreased manganese levels in these mutants. Growth of both mutants was significantly improved by the addition of $10 \mu \mathrm{M} \mathrm{Mn}^{2+}$ (Figure 2C-D).

We next wanted to determine how the reduced $\mathrm{pH}$ affected manganese levels in these strains. In our accompanying study (Puccio et al., 2021a), we determined the average manganese levels of 
the SK36 strains in BHI pH 7.3 using inductively coupled plasma optical emission spectroscopy (ICP-OES), which are reproduced in Figure 3A. The mean levels of manganese were lower in these strains in BHI at pH 6.2 (Figure 3B); so much so that levels in both $\triangle s s a A C B$ and $\triangle s s a A C B \triangle t m p A$ fell below the limit of detection unless exogenous $\mathrm{Mn}^{2+}$ was added. While there was a significant difference between the $\triangle s s a A C B \triangle t m p A$ mutant and its parent when $10 \mu \mathrm{M}$ $\mathrm{Mn}^{2+}$ was added at $\mathrm{pH} 7.3$ (Figure $3 \mathrm{~A}$ ), there were no significant differences between either parent strain (WT or $\triangle s s a A C B$ ) and its corresponding $\triangle t m p A$ mutant in any condition at $\mathrm{pH} 6.2$ (Figure 3B). Levels of the biologically relevant metals iron (Fe), zinc $(\mathrm{Zn})$, and magnesium $(\mathrm{Mg})$ were not significantly affected by the lack of tmpA in either the WT or $\triangle s s a A C B$ background in $\mathrm{BHI}$ at pH 7.3 (Puccio et al., 2021a) or pH $6.2 \pm 10 \mu \mathrm{M} \mathrm{Mn}^{2+}$ (Figure S1A, C, E).

138 Manganese levels of VMC66 and derivative strains in BHI at pH 7.3 were also measured in 139 Puccio et al. (2021a) and are shown in Figure 3C. With the exception of both $\Delta m n t H$ strains, the mean manganese levels at pH 6.2 (Figure 3D) were higher than at pH 7.3. The loss of TmpA did not impact manganese levels in either the WT VMC66 or the $\triangle s s a A C B$ mutant under either $\mathrm{pH}$ condition. Levels of iron, zinc, and magnesium were not significantly affected by deletion of the tmpA or $m n t H$ gene in either the WT or $\triangle s s a A C B$ background at pH 7.3 (Puccio et al., 2021a) or 144 pH 6.2 (Figure S1B, D, F).

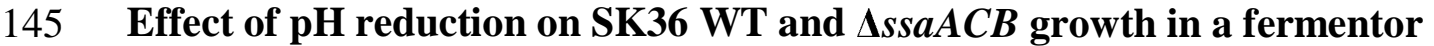

146 To assess the effect of reduced $\mathrm{pH}$ on the transcriptome of SK36 WT and $\triangle s s a A C B$ mutant cells, 147 we employed the use of a fermentor (Figure S2). To minimize the impact of oxidative stress, we 148 used the minimum possible airflow $(0.03 \mathrm{lpm})$ throughout the experiment. We were unable to 149 turn off the air entirely because cultures without airflow grew poorly (data not shown). Cells 150 were grown at $\mathrm{pH} 7.4$ ( $\mathrm{pH}$ of human blood) until the OD peaked, and then for $1 \mathrm{hr}$ with a media 151 flow rate of $700 \mathrm{~mL} \mathrm{~h}^{-1}$ before collection of the $\mathrm{T}_{-20}$ min sample for RNA-seq. Twenty minutes 152 later $\left(\mathrm{T}_{0}\right)$, the $\mathrm{pH}$ was changed to 6.2 by addition of $2 \mathrm{~N} \mathrm{HCl}$ and $2 \mathrm{~N} \mathrm{KOH}$ in response to the 153 output from an indwelling $\mathrm{pH}$ probe. A $\mathrm{pH}$ of 6.2 was chosen because it did not affect WT 154 (Figure S2A) but led to a decrease in growth rate of the $\triangle s s a A C B$ mutant as evidenced by the drop in OD (Figure S2B). Under constant-flow conditions, a drop in OD is expected when a culture's doubling rate drops below its dilution rate (Burne \& Chen, 1998). Samples at pH 6.2 were removed at $\mathrm{T}_{10}, \mathrm{~T}_{25}$, and $\mathrm{T}_{50}$ min and RNA was isolated for RNA-seq analysis.

158 We next wanted to determine if manganese levels were affected by $\mathrm{pH}$ reduction in the 159 fermentor. We assessed the metal content of cells at each sample time point using ICP-OES

160 (Figure 4). Manganese levels significantly decreased in both strains, further confirming that 161 reduced $\mathrm{pH}$ conditions are not conducive to manganese transport. Interestingly, iron levels 162 appeared to increase in both strains after acid addition, albeit not significantly. Magnesium 163 increased significantly at $\mathrm{T}_{50}$ only in the $\triangle s s a A C B$ mutant strain. Zinc levels were slightly lower 164 at $\mathrm{T}_{50}$ but this difference was not significant in either strain.

165 To determine if reduced manganese uptake was the primary cause of the growth deficiency after $166 \mathrm{pH}$ reduction in the fermentor as it appeared to be in tube cultures, we added $\mathrm{Mn}^{2+}$ to a final 167 concentration of $10 \mu \mathrm{M}$ at $\mathrm{T}_{70}$ in additional fermentor runs (Figure S3). As the WT strain was not 168 deficient in growth at $\mathrm{pH}$ 6.2, no restoration of growth was apparent (Figure S3A). The addition 
169 of $\mathrm{Mn}^{2+}$ led to a recovery in the growth rate of the $\triangle s s a A C B$ mutant as expected (Figure $\mathrm{S} 3 \mathrm{C}$ ). 170 When metal analysis was performed on these runs, it was observed that manganese levels 10 min 171 after $\mathrm{Mn}^{2+}$ addition $\left(\mathrm{T}_{80}\right)$ increased $\sim 5$-fold in WT (Figure S3B) but approximately doubled in 172 the $\triangle s s a A C B$ mutant (Figure $\mathrm{S} 3 \mathrm{D}$ ). These results suggest that $\triangle s s a A C B$ mutant cells were still 173 viable at the latest time point $\left(\mathrm{T}_{50}\right)$, despite the drop in $\mathrm{OD}$, since they were capable of resuming 174 metal uptake and growth 20 min later after the addition of $\mathrm{Mn}^{2+}$.

175 RNA-seq analysis of fermentor-grown SK36 WT and $\triangle s s a A C B$ cells before and after pH 176 reduction

177 In an attempt to determine the cause of the growth arrest of the $\triangle s s a A C B$ mutant, we examined 178 the transcriptome of fermentor-grown WT and $\triangle s s a A C B$ cells taken at the same time points as 179 described above. We examined the results of the RNA-seq analysis using three comparisons: 180 within-strain comparisons of each $\mathrm{pH} 6.2$ time point to $\mathrm{pH} 7.4\left(\mathrm{~T}_{-20}\right)$ for (1) WT and (2) the $181 \triangle s s a A C B$ mutant (Error! Reference source not found.-S2), and (3) comparison of the WT and $182 \triangle s s a A C B$ mutant strains at each time point (Error! Reference source not found.). The number 183 of differentially expressed genes (DEGs; defined as $P \leq 0.05, \mid \log _{2}$ fold change $\geq 1$ ) for each 184 comparison are listed in Figure 5A. Using principal component analysis (PCA), we were able to 185 demonstrate that each sample grouped with the others from the same time point, indicating that 186 the results were reproducible and had minimal variability (Figure S4A-B). The 95\% confidence 187 intervals for the $\mathrm{pH} 6.2$ sample time points of the WT strain overlapped with each other (Figure $188 \mathrm{~S} 4 \mathrm{~A}$ ), whereas those for $\triangle s s a A C B$ did not (Figure S4B). The $\mathrm{pH} 7.4$ samples were well separated 189 from the pH 6.2 samples in both strains. When all samples were examined together (Figure S4C), 190 the sample groups for both strains overlapped one another at each time point, although the WT $191 \mathrm{~T}_{50}$ group overlapped more with the $\triangle s s a A C B \mathrm{~T}_{25}$ samples than those of $\mathrm{T}_{50}$ (Figure $\mathrm{S} 4 \mathrm{C}$ ). These 192 results correspond with the volcano plots (Figure S5) and heatmaps (Figure S6). Most of the 193 expression changes occurred at the $\mathrm{T}_{50}$ time point for both strains, although there were fewer 194 changes in WT than $\triangle s s a A C B$. When comparing the strains to each other, the $\mathrm{T}_{10}$ and $\mathrm{T}_{25}$ time 195 points were almost identical, whereas $\mathrm{T}_{-20}$ and $\mathrm{T}_{50}$ time points had more variation (Figure $5 \mathrm{~A}$ ).

196 To begin to assess the cause of the growth arrest resulting from addition of acid, we evaluated the expression of stress response genes. As expected, the expression of genes encoding an alkaline stress protein (SSA_2148), exinulcease subunit A ( $u v r A$ ), and all subunits of the $\mathrm{F}_{0} \mathrm{~F}_{1^{-}}$ Type ATP synthase (Kuhnert \& Quivey, 2003) significantly increased in the $\triangle s s a A C B$ mutant. Most other putative stress response genes were decreased or unchanged (Error! Reference source not found.). Notably, expression of the gene encoding superoxide dismutase, sodA, was slightly decreased. Although not unprecedented (Santi et al., 2009), there is a strong connection between SodA and acid stress response in other bacteria (Kim et al., 2005, Bruno-Barcena et al., 2010). We presumed that the opposite response observed for $\operatorname{sodA}$ in our study was due to the reduced manganese levels in the $\triangle s s a A C B$ mutant, because we showed in our previous study (Puccio et al., 2020) that sodA expression is manganese dependent. Indeed, in WT cells, expression levels rose slightly. We thus considered that the unusual decrease in sodA expression might have contributed to the growth arrest of $\triangle s s a A C B$ cells. We therefore tested the growth of a previously generated $\triangle \operatorname{sod} A$ mutant (Crump et al., 2014) in the fermentor under identical conditions, but growth was not affected (data not shown). Apart from $\operatorname{sodA}$, these stress response 
genes had similar expression patterns in WT (Error! Reference source not found.), although changes were often of lower magnitude.

213 In examining the KEGG pathways assigned to the DEGs at $\mathrm{T}_{50}$, genes involved in phosphotransferase systems (PTS), biosynthesis of amino acids (specifically arginine and histidine), and oxidative phosphorylation were significantly affected by $\mathrm{pH}$ reduction in both strains. The most highly enriched pathway for the $\triangle s s a A C B$ mutant was the "Porphyrin/Chlorophyll" pathway but upon examination, these genes encode the cobalamin biosynthetic enzymes (Error! Reference source not found.), which were also significantly downregulated in our recent study of manganese depletion (Puccio et al., 2020). Many of the pathways highlighted by this analysis, such as carbon metabolism and amino acid metabolism, were also affected by manganese reduction in our recent transcriptomic and metabolomic studies (Puccio et al., 2020, Puccio et al., 2021b). We observed significant decreases in the expression of sugar transport genes (Error! Reference source not found.). This led us to evaluate whether acidic conditions could also lead to glucose-independent CcpA-mediated carbon catabolite repression. We examined expression of all genes found to be within the CcpA-regulon (Bai et al., 2019) as well as those that we identified that have putative upstream cre sites (Puccio et al., 2020). We found that 75 of the 382 genes with putative cre sites (19.6\%) were significantly downregulated in the $\triangle s s a A C B$ mutant at $\mathrm{T}_{50}$, whereas 30 were upregulated $(7.9 \%$ ) (Error! Reference source not found.). In WT, 47 (11.7\%) were downregulated and 13 (3.4\%) were upregulated. In our manganese-depletion transcriptomic study (Puccio et al., 2020), we found that $19.9 \%$ of genes with putative cre sites were downregulated at $\mathrm{T}_{50}$, although the genes downregulated in the $\triangle s s a A C B$ mutant under both conditions don't match precisely. For example, $s p x B$ was significantly upregulated in reduced $\mathrm{pH}$ (Error! Reference source not found.) but significantly downregulated in reduced manganese (Puccio et al., 2020). This indicates that while there may be some overlap due to the decrease in manganese levels in both studies, there are also changes that are specific to $\mathrm{pH}$ reduction.

237 As acid stress tolerance has been previously linked to amino acid biosynthesis and transport 238 (Quivey et al., 2001, Djoko et al., 2017, Guan \& Liu, 2020, Senouci-Rezkallah et al., 2011), we evaluated the expression of genes annotated with these functions (Error! Reference source not found.). Many of these genes were significantly affected by acid addition, although more were affected in the $\triangle s s a A C B$ mutant. Of note, aconitate hydratase, citrate synthase, and isocitrate dehydrogenase were significantly upregulated in the $\triangle s s a A C B$ mutant but significantly downregulated in the WT strain at $\mathrm{T}_{50}$ (Error! Reference source not found.).

Biofilm competition of the $S$. sanguinis SK36 WT and $\triangle s s a A C B$ strains against $S$. mutans in vitro

After examining the effect of reduced manganese on gene expression and loss of manganese transporters on growth and metal content, we decided to assess whether the lack of the primary manganese transporter would have relevance to growth conditions similar to those found in the oral cavity. We therefore compared the growth of a spectinomycin (Spc) resistant SK36 WT strain, JFP56, to the $\triangle s s a A C B$ mutant in competition with $S$. mutans (Figure 6). Given that $S$. mutans often outcompetes WT $S$. sanguinis if given the opportunity to colonize first, we 252 inoculated wells of biofilm media $(\mathrm{BM})+1 \%$ sucrose with $S$. sanguinis to stimulate biofilm 253 formation and allowed $24 \mathrm{~h}$ of aerobic growth. We then refreshed the wells with Tryptone Yeast 254 Extract $+1 \%$ sucrose $(\mathrm{TY}+\mathrm{S})$ and inoculated with an $S$. mutans strain containing a plasmid- 
encoded erythromycin (Erm) resistance gene. After another $24 \mathrm{~h}$ incubation, we then measured the $\mathrm{pH}$ of the media and plated the biofilm cultures. $S$. mutans growth was unaffected by the presence of $S$. sanguinis (Figure 6A), whereas both $S$. sanguinis strains were recovered in significantly lower numbers in the presence of $S$. mutans (Figure 6B). In fact, only one of six replicates of the $\triangle s s a A C B$ mutant produced a single colony after incubation in the presence of $S$. mutans. The $\mathrm{pH}$ of all culture supernatants after $24 \mathrm{~h}$ growth in $\mathrm{TY}+\mathrm{S}$ was significantly lower than media alone, with the $S$. mutans supernatant averaging $\mathrm{pH} 4.08$ and the $S$. sanguinis WT and $\triangle$ ssaACB supernatants averaging $\mathrm{pH} 4.50$ and 4.58, respectively (Figure 6C).

\section{Contribution of SsaACB to oral colonization and competition in a murine model}

264 Given the results of the in vitro competition assay, we used an in vivo model to compare colonization of the oral cavity and dental biofilms by the SK36 WT and $\triangle$ ssaACB mutant strains, and once colonization was established, we then compared the ability of each strain to compete against S. mutans under cariogenic conditions. We employed the mouse model described recently by Culp et al. (2020) with mice fed a diet containing 37.5\% sucrose. After antibiotic suppression of the oral microbiota, each of two groups of mice received five daily oral inoculations with one of the two $S$. sanguinis test strains, followed two weeks later by challenge with $S$. mutans. Oral swabs were taken at weekly intervals, thus providing a measure of colonization within saliva and the oral mucosal pellicle, with subsequent sonication of mandibular molars to assess bacteria recovered from dental biofilms (see timeline of events, Figure 7A). Recoveries of bacteria released from swabs and molar sonicates were determined by strain-specific qPCR assays of genomic DNA, plus estimates of total recovered bacteria were determined by qPCR assay of the ubiquitous single copy gene, $r p s L$ (30S ribosomal protein S12). Subtraction of strain-specific recoveries from total recovered bacteria allowed estimations of the population of recovered murine oral commensal bacteria. We observed that both S. sanguinis strains colonized well in competition with native mouse commensals (Figure 7B). Upon introduction of $S$. mutans, the abundance of the two test strains and the mouse commensals declined and then recovered by the following week. When levels of the two test strains were compared for each time point, we found that the $\triangle s s a A C B$ mutant was recovered from the molars at slightly, yet significantly lower levels than WT 14 days after the introduction of $S$. mutans (experimental day 28). The mouse commensal species present in each animal group were also compared to one another at each time point and were only found to be significantly different on the molars of mice inoculated with the $\triangle s s a A C B$ mutant. $S$. mutans levels were slightly but not significantly higher in competition with SK36 WT at day 27 (swab 5) than in competition with the $\triangle s s a A C B$ mutant on the same day. These results suggest that SsaACB had no impact on oral colonization and was of only minor importance for dental colonization and competition, even in a strain that did not possess the $m n t H$ gene. This is in stark contrast to the results obtained from our in vivo endocarditis model showing that the SsaACB transporter is essential for virulence, even in strains possessing TmpA and MntH transporters (Puccio et al., 2021a).

\section{Discussion}

294 While a relationship between manganese and acid tolerance in streptococci has been suggested 295 previously (Shabayek \& Spellerberg, 2017, Kajfasz et al., 2020), it has yet to be fully 296 characterized. Beighton (1982) noted that manganese induced S. mutans to form caries and 
influenced carbohydrate metabolism. In Streptococcus pneumoniae (Martin-Galiano et al., 2005) and S. agalactiae (Santi et al., 2009), the orthologs of SsaACB were upregulated in response to acid stress. In $S$. mutans, expression of the manganese-dependent regulator SloR was previously linked to ATR (Dunning et al., 2008). Recently, it was appreciated that loss of MntH in $S$. mutans (Kajfasz et al., 2020) and S. agalactiae (Shabayek et al., 2016) led to a reduction in acid tolerance. Here we report that loss of the high-affinity manganese ABC transporter in $S$. sanguinis strain SK36, SsaACB, reduces acid tolerance but does not greatly influence oral colonization or competition with $S$. mutans. We also characterize the transcriptional changes that accompany the growth arrest of the $\triangle s s a A C B$ mutant observed in reduced $\mathrm{pH}$ conditions in vitro and in comparison with WT.

Initially, we were unsure whether the growth arrest we observed in the $\triangle s s a A C B$ mutant was directly related to manganese, but the reduction in intracellular manganese levels in both WT and $\triangle s s a A C B$ strains in tube cultures (Figure 3) and fermentor cultures (Figure 4) indicates that reduced $\mathrm{pH}$ affects the ability of manganese to enter the cell. No other biologically relevant metal significantly decreased in cells at pH 6.2 (Figure S1), further highlighting the relationship between manganese and reduced $\mathrm{pH}$. Mean iron levels increased in both strains in the fermentor after $\mathrm{pH}$ reduction, albeit not significantly (Figure 4). These correspond to increases in the expression of genes encoding putative iron transporters (Tables S1-S2), such as those encoded by SSA_RS07705-SSA_RS07715. Similarly, the significant increase in magnesium levels in the $\triangle s s a A C B$ mutant may be due to an increase in expression of SSA_RS03540 (Table S2), which encodes a putative magnesium-transport protein, CorA (Kehres et al., 1998). Moreover, the addition of as little as $1 \mu \mathrm{M} \mathrm{Mn}^{2+}$ restored the growth of the $\triangle$ ssaACB mutant to WT-like levels, suggesting that this is likely the main reason for the growth arrest observed at $\mathrm{pH}$ 6.2. Furthermore, many transcriptomic responses to $\mathrm{pH}$ reduction were similar to those of manganese reduction by EDTA (Puccio et al., 2021a).

322 We hypothesized that either the function of a secondary manganese transporter, TmpA, is negatively affected by reduced $\mathrm{pH}$ or that bioavailability of manganese is affected. The ortholog of TmpA in E. coli, ZupT, functions best near neutral pH (Taudte \& Grass, 2010). Several lines of evidence in this study suggest that at $\mathrm{pH} 6.2$, TmpA loses the ability to transport manganese efficiently. We found that manganese levels in a $\triangle s s a A C B \triangle t m p A$ mutant strain were indistinguishable from those in the $\triangle s s a A C B$ parent in $\mathrm{BHI}$ at $\mathrm{pH} 6.2 \pm 10 \mu \mathrm{M} \mathrm{Mn}^{2+}$ (Figure $3 \mathrm{~B}$ ), which was not true at pH 7.3 (Figure 3A). Moreover, manganese levels of both strains at $\mathrm{pH} 6.2$ were very similar to levels in the $\triangle s s a A C B \triangle t m p A$ mutant at $\mathrm{pH} 7.3$, suggesting that growth at $\mathrm{pH} 6.2$ has an effect equivalent to deletion of the tmpA gene. Additionally, growth of the SK36 $\triangle s s a A C B$ and $\triangle s s a A C B \triangle t m p A$ mutants were indistinguishable at $\mathrm{pH} 6.2$ and reached a final density that was similar to that of the $\triangle s s a A C B \triangle t m p A$ mutant at $\mathrm{pH} 7.3$, again suggesting that growth at $\mathrm{pH} 6.2$ has the same effect as deletion of the tmpA gene. Finally, when strains that possess a NRAMP protein $(\mathrm{MntH})$, such as VMC66, are deleted for ssaACB, they do not experience a decrease in manganese levels or growth at $\mathrm{pH} 6.2$, in agreement with expectations if one assumes the activity of TmpA is greatly diminished at this $\mathrm{pH}$ and that of $\mathrm{MntH}$ is not. Taken together, these results strongly support the hypothesis that reductions in growth and 338 manganese levels of SK36 and its $\triangle s s a A C B$ mutant at $\mathrm{pH} 6.2$ are due to the reduced function of 339 TmpA (Figure 8), although studies with cell-free liposomes will be required for confirmation.

340 Due to the short time frame of our transcriptional analysis (50 $\mathrm{min})$, we believe that the changes observed are an acid shock response, as opposed to acid adaptation (Quivey et al., 2001). 
However, acid shock responses have typically employed a pH of 3.0 to 4.4 (Martin-Galiano et al., 2005, Hamilton \& Svensäter, 1998) so given that the growth rate of WT is unchanged and that we used a modest reduction in $\mathrm{pH}(6.2)$, it is likely a relatively mild response. When comparing the reduced-pH RNA-seq results in each strain directly to the other, few DEGs were observed and those that were occurred only at the $\mathrm{T}_{-20}$ and $\mathrm{T}_{50}$ time points (Figure 5A). Despite these results, we observed a drastic difference in the fermentor growth rate between WT and $\triangle s s a A C B$ after acid addition (Figure S2). Thus, we hypothesize that either subtle changes between strains have a large combined effect or post-transcriptional changes not captured by transcriptomics may be influencing the growth. It is also possible that both explanations are correct. One reason for the changes being small could be that WT and $\triangle$ ssaACB are both experiencing two, typically separate stresses-acid stress and manganese depletion-although SK36 is experiencing both to a lesser degree. Examination of the manganese levels of WT cells in unsupplemented batch cultures at $\mathrm{pH} 7.3$ vs. 6.2 (Figure 3A vs. 3B) and fermentor cultures before and after acid addition (Figure 4A) suggests that even with SsaACB intact, WT cells take up less manganese at $\mathrm{pH} 6.2$ than 7.3. This is also supported by the increase in expression of $s s a B$, ssaC, and ssaA (SSA_RS01450-01460) after acid addition in the fermentor (Table S1). However, it is also clear that both strains exhibit expression changes expected in response to reduced $\mathrm{pH}$, as discussed previously. It would not be surprising if the effects of the two stresses were additive or synergistic with regard to growth inhibition. Thus, expression changes would be spread over two stress responses rather than one, further diminishing the importance or magnitude of any one expression difference.

363 We recently reported that manganese depletion led to induction of carbon catabolite repression in S. sanguinis (Puccio et al., 2020, Puccio et al., 2021b). Given that both addition of acid and EDTA (Puccio et al., 2021b) led to reduced manganese levels in the fermentor (Figure 4), we hypothesize that the impact on glycolysis is similar to what we observed in our previous study. Additionally, expression of genes encoding glycolytic enzymes responded similarly in both studies (Error! Reference source not found.), indicating that the regulatory mechanisms controlling the expression of these genes may have a manganese-related aspect. Thus we hypothesize that there is likely an accumulation of FBP occurring in cells growing at reduced $\mathrm{pH}$ due to reduced activity of Fba, Fbp, or both enzymes (Puccio et al., 2021b). This may be the cause behind the changes in expression we observed in the CcpA regulon (Error! Reference source not found.). As noted by Radin et al. (2016), glycolytic enzymes may have a higher demand for manganese than other enzymes and thus in manganese-deplete conditions, the cells may shift to amino acid metabolism as a source of energy. This could explain why we observed significant increases in expression of many amino acid biosynthetic and transport genes (Error! Reference source not found.). However, the impact of PTS, CcpA, and central carbon metabolism on gene expression are complex, and it is likely that multiple factors impact the expression of CCR-responsive genes.

Acid is an important component of the competition between $S$. sanguinis and $S$. mutans in vitro (Kreth et al., 2005). While not significant, the difference in the mean levels of SK36 WT and $\triangle s s a A C B$ mutant growth in direct competition with $S$. mutans in in vitro biofilms was appreciable, especially given that the $\triangle s s a A C B$ mutant was only recovered in one out of six replicates. Our in vivo study yielded no significant differences in recoveries from oral swabs, a measure of colonization of oral mucosal epithelia (Culp et al., 2020), and only slight, yet significant differences between the SK36 WT and $\triangle s s a A C B$ mutant strains in colonization of 
dental biofilms when in competition with $S$. mutans. It was recently shown using the same mouse model that clinical isolates of streptococci from dental plaque of caries-free individuals (i.e., Streptococcus mitis, Streptococcus gordonii, Streptococcus A12), which in vitro were highly competitive against $S$. mutans, poorly colonized oral mucosal and dental biofilms, while two strains of $S$. sanguinis suppressed initial mucosal colonization by $S$. mutans and persisted in both biofilms, even as $S$. mutans recovered to levels observed in a control group of mice challenged with S. mutans alone (Culp et al., 2020). Moreover, both strains of S. sanguinis promoted dental colonization of mouse commensals to levels equivalent or higher than $S$. mutans, similar to the SK36 WT and $\triangle s s a A C B$ mutant strains in the current study. Additionally, oral colonization of SK36 WT and its $\triangle s s a A C B$ mutant quickly recovered after being initially suppressed when challenged with $S$. mutans, suggesting that persistent colonization of mucosal biofilms may serve as a reservoir for colonization of dental biofilms. In clinical studies, S. sanguinis was shown to precede and delay colonization by $S$. mutans of newly acquired teeth in children (Caufield et al., 2000) and to persist in cavitated lesions in which $S$. mutans accounted for up to $55 \%$ of the microbiota (Gross et al., 2012). Collective evidence therefore indicates S. sanguinis is well adapted to the oral cavity and dental biofilms in which it copes with innate immune factors in saliva, interacts with other oral commensals either competitively or cooperatively, and importantly can coexist with S. mutans under cariogenic conditions. Although the SsaACB transport system appears to be universally conserved in $S$. sanguinis strains, its importance was not demonstrable under in vivo conditions.

We propose three possible explanations for the in vivo results. One is that SsaACB wasn't necessary because the oral environment contained sufficient manganese or had a $\mathrm{pH}$ close enough to neutral to allow comparable growth of the WT and $\triangle s s a A C B$ strains using only the TmpA transporter over the course of this experiment. Secondly, as described above from the work of Radin et al. (2016), a shift to amino acid metabolism as a source of energy may have lessened the demand for manganese under conditions of manganese depletion. It has been shown that interactions of oral commensal species and $S$. mutans with surface-associated salivary constituents induces a more protease-active phenotype capable of more effectively degrading salivary proteins and mucin glycoproteins (Kindblom et al., 2012, Wickström et al., 2013), thus potentially providing a reliable source of amino acids for uptake and metabolism. Another is that perhaps there is some aspect of the oral cavity environment that reduces the activity or expression of SsaACB. In this case, SsaACB would not be capable of making a strong contribution, so the WT strain would compete only slightly better than the mutant. While this explanation seems inherently less plausible, we cannot rule it out at present. If true, it could account for the existence of TmpA in S. sanguinis, which is otherwise inexplicable. Moreover, although we have not yet tested the effect of $\mathrm{MntH}$ in an oral model, the fact that it seems to be most active under exactly the conditions in which TmpA is least active (Figure 8) provides a rationale for its presence in some strains.

425 In conclusion, these results indicate that SsaACB made no more than a minor contribution to 426 competitiveness in this model, despite the fact that the only other transporter, TmpA, has now 427 been found to be inactive at reduced $\mathrm{pH}$. These results may guide future studies. For example, 428 there has been much interest concerning the development of probiotic bacteria for promotion of 
oral health. Given the results of the studies employing the endocarditis model in the accompanying paper (Puccio et al., 2021a) in combination with the murine studies reported here, and the work with the $\triangle m n t H$ mutant of VMC66, one course of action would be to begin with a promising $m n t H$-containing $S$. sanguinis strain or candidate probiotic species such as Streptococcus sp. A12 (Lee et al., 2019), then delete ssaACB. This mutant could be tested in a similar manner to the experiments described here and in the accompanying paper to ensure the same behavior of the mutants. Additionally, these data suggest that an SsaB inhibitor may be effective at preventing IE while leaving the oral flora intact. Therefore, an IE patient with a healthy oral microbiota could take a small-molecule SsaB inhibitor to prevent IE with less concern of shifting the oral microbiota in favor of caries. Furthermore, IE patients with high risk for dental caries could take a probiotic in addition to the SsaB inhibitor without additional risk of IE. In conclusion, these results and those of the accompanying study (Puccio et al., 2021a) enhance the understanding of the role of manganese in S. sanguinis and highlight this essential nutrient as an important factor for consideration in the development of streptococcal therapeutics.

\section{Experimental Procedures}

\section{Bacterial strains}

446 Strains and plasmids used in this study are listed in Table 1. All strains were grown in overnight cultures from single-use aliquots of cryopreserved cells, diluted 1000-fold in BHI media (Beckinson Dickinson). Mutant strains were incubated with the appropriate antibiotics: kanamycin (Kan; Sigma-Aldrich) $500 \mathrm{ug} \mathrm{mL}^{-1}$; erythromycin (Erm; Sigma-Aldrich); $10 \mu \mathrm{g} \mathrm{mL}^{-1}$; spectinomycin (Spc; Sigma-Aldrich) $200 \mu \mathrm{g} \mathrm{mL}^{-1}$; chloramphenicol $\left(\mathrm{Cm}\right.$; Fisher) $5 \mu \mathrm{g} \mathrm{mL}^{-1}$. The pre-cultures of the SK36 $\triangle s s a A C B \triangle t m p A$ and VMC66 $\triangle s s a A C B \triangle m n t H$ mutants required exogenous $\mathrm{Mn}^{2+}(10 \mu \mathrm{M})$ for growth. The cultures were then incubated at $37^{\circ} \mathrm{C}$ for $16-20 \mathrm{~h}$ with the atmospheric condition set to $1 \% \mathrm{O}_{2}\left(9.5 \% \mathrm{H}_{2}, 9.5 \% \mathrm{CO}_{2}\right.$, and $\left.80 \% \mathrm{~N}_{2}\right)$ or $6 \% \mathrm{O}_{2}\left(7 \% \mathrm{H}_{2}, 7 \%\right.$ $\mathrm{CO}_{2}$, and $80 \% \mathrm{~N}_{2}$ ) using a programmable Anoxomat ${ }^{\mathrm{TM}}$ Mark II jar-filling system (AIG, Inc).

\section{Tube growth studies}

The $\mathrm{pH}$ of $\mathrm{BHI}$ was modified by addition of $6 \mathrm{~N} \mathrm{HCl}$ prior to autoclaving. Each tube was preincubated at $37^{\circ} \mathrm{C}$ in $1 \% \mathrm{O}_{2}$ in an Anoxomat jar overnight, then inoculated with a $10^{-6}$-fold dilution of the overnight pre-culture. The inoculated tubes were returned to incubate at $37^{\circ} \mathrm{C}$ in $1 \% \mathrm{O}_{2}$. In some growth studies, $\mathrm{MnSO}_{4}$ (Alfa Aesar; Puratronic ${ }^{\mathrm{TM}}$, $>99.999 \%$ pure) was added to culture tubes immediately prior to inoculation. To determine CFUs, samples were sonicated for $90 \mathrm{~s}$ using an ultrasonic homogenizer (Biologics, Inc) to disrupt chains. Cultures were diluted in PBS and plated on BHI agar (Beckinson Dickinson) plates using an Eddy Jet 2 spiral plater (Neutec Group, Inc.). Plates were incubated for $24 \mathrm{~h}$ at $37^{\circ} \mathrm{C}$ under anaerobic conditions with a palladium catalyst included in the jars.

\section{Metal analysis}

For metal analysis of cells growing batch cultures, 2 tubes of $38 \mathrm{~mL}$ of BHI per strain and condition were pre-incubated at $37^{\circ} \mathrm{C}$ overnight. For some samples, $\mathrm{Mn}^{2+}$ was added to $10 \mu \mathrm{M}$ immediately prior to inoculation. Pre-cultures $(3 \mathrm{~mL})$ were added to each tube. For $\mathrm{pH} 7.3$ samples, pre-cultures were added directly. For $\mathrm{pH} 6.2$ samples, pre-cultures were centrifuged and resuspended in $\mathrm{pH} 6.2 \mathrm{BHI}$ prior to inoculation. Cultures were grown to mid-logarithmic phase and centrifuged at $3,740 \times \mathrm{g}$ for $10 \mathrm{~min}$ at $4^{\circ} \mathrm{C}$. All strains grew under the conditions of this 
assay; however, some of the mutants grew slower than the WT strains. For fermentor samples, aliquots of $40 \mathrm{~mL}$ were collected at each time point and then centrifuged as described above.

474 The collected cell pellet was then washed twice with cold cPBS (PBS treated with Chelex-100 resin (Bio-Rad) for $2 \mathrm{~h}$, then filter sterilized and supplemented with EDTA to $1 \mathrm{mM}$ ). The pellet was then divided for subsequent acid digestion or protein concentration determination. Trace metal grade (TMG) nitric acid (15\%) (Fisher Chemical) was added to one portion of the pellet. The pellet was digested using an Anton Paar microwave digestion system using a modified Organic B protocol: $120^{\circ} \mathrm{C}$ for $10 \mathrm{~min}, 180^{\circ} \mathrm{C}$ for $20 \mathrm{~min}$, with the maximum temperature set to $180^{\circ} \mathrm{C}$. The digested samples were then diluted 3-fold with Chelex-treated $\mathrm{dH}_{2} \mathrm{O}$. Metal concentrations were determined using an Agilent 5110 inductively coupled plasma-optical emission spectrometer (ICP-OES). Concentrations were determined by comparison with a standard curve created with a $10 \mu \mathrm{g} \mathrm{ml}^{-1}$ multi-element standard (CMS-5; Inorganic Ventures) diluted in 5\% TMG nitric acid. Pb (Inorganic Ventures) was used as an internal standard (100 $\mu \mathrm{g}$ $\mathrm{ml}^{-1}$ ). The other portion of the pellet was resuspended in PBS and mechanically lysed using a FastPrep-24 instrument with Lysing Matrix B tubes (MP Biomedicals) as described previously (Rhodes et al., 2014). Insoluble material was removed by centrifugation. Protein concentrations were determined using a bicinchoninic acid (BCA) Protein Assay Kit (Pierce) as recommended by the manufacturer, with bovine serum albumin as the standard.

\section{$490 \quad$ Fermentor growth conditions}

491 The fermentor conditions were similar to Puccio and Kitten (2020) with minor modifications. A BIOSTAT® B bioreactor (Sartorius Stedim) with a 1.5-L capacity UniVessel ${ }^{\circledR}$ glass vessel was used for growth of $800-\mathrm{mL}$ cultures at $37^{\circ} \mathrm{C}$. Cultures were stirred at $250 \mathrm{rpm}$ and $\mathrm{pH}$ was maintained by the automated addition of $2 \mathrm{~N} \mathrm{KOH}$ and $2 \mathrm{~N} \mathrm{HCl}$ (Fisher Chemical). A 40-mL overnight pre-culture of $S$. sanguinis was grown as described above and centrifuged for 10 minutes at 3,740 $x \mathrm{~g}$ in an Allegra X-142 centrifuge at $4^{\circ} \mathrm{C}$. The supernatant was discarded and the cells were resuspended in $\mathrm{BHI}$ prior to inoculation. The air flow was kept at $0.03 \mathrm{lpm}$ for the entire experiment. Once the cells reached their peak OD in static culture, the input flow of BHI was set to $17 \%\left(\sim 700 \mathrm{~mL} \mathrm{~h}^{-1}\right)$, and the output flow of waste was set to $34 \%$ for the remainder of the experiment. Cells were allowed to acclimate to this media flow rate for $1 \mathrm{~h}$. The $\mathrm{T}_{-20}$ sample was aseptically removed for total RNA isolation or metal analysis. The fermentor culture in the vessel was adjusted to $\mathrm{pH} 6.2$ using an in-dwelling probe at $\mathrm{T}_{0}$. Samples were taken for each post-treatment time point $\left(\mathrm{T}_{10}, \mathrm{~T}_{25}, \mathrm{~T}_{50}\right)$. In some experiments, $\mathrm{MnSO}_{4}$ (Puratronic ${ }^{\mathrm{TM}}$; Alfa

504 Aesar) was added to the carboy $\left(\mathrm{T}_{66}\right)$ and vessel $\left(\mathrm{T}_{70}\right)$ at a final concentration of $10 \mu \mathrm{M}$ and

505 samples were taken for metal analysis at $\mathrm{T}_{80}$.

\section{RNA isolation}

507 Fermentor samples (2 mL) were added to $4 \mathrm{~mL}$ RNAprotect Bacteria Reagent (Qiagen) and 508 immediately vortexed for $10 \mathrm{~s}$. The samples were then incubated at room temperature for 5-90 $509 \mathrm{~min}$ and centrifuged for $10 \mathrm{~min}$ at $3,740 \mathrm{x} \mathrm{g}$ at $4^{\circ} \mathrm{C}$. The supernatant was discarded and the 510 samples stored at $-80^{\circ} \mathrm{C}$. RNA isolation and on-column DNase treatment were completed using 511 the RNeasy Mini Kit and RNase-Free DNase Kit, respectively (Qiagen). RNA was eluted in 50 $512 \mu \mathrm{L}$ RNase-Free water (Qiagen). A second DNase treatment was then performed on the samples 513 (Invitrogen). 


\section{RNA sequencing}

515 Total RNA quantity and integrity were determined using a Bioanalyzer (Agilent). All samples passed quality control assessment with RNA Integrity Numbers (RIN) above 8. Two sequential rounds of ribosomal reduction were then performed on all samples using RiboMinus ${ }^{\mathrm{TM}}$ Transcriptome Isolation Kit (ThermoFisher). The resulting depleted RNA was assessed using Bioanalyzer (Agilent) to confirm efficient rRNA removal. Stranded RNA-seq library construction was then performed on the rRNA-depleted RNA using the Kapa RNA HyperPlus kit for Illumina (Roche) following manufacturer's specifications for library construction and multiplexing. Final Illumina libraries were assessed for quality using an Agilent Bioanalyzer DNA High Sensitivity Assay and qPCR quantification was performed using Kapa Library Quantification kit for Illumina (Roche). Individual libraries were pooled equimolarly and the final pool was sequenced on an Illumina MiSeq with 2 x 75-bp paired-end reads. Demultiplexing was performed on the Illumina MiSeq's on-board computer. The Virginia Commonwealth University Genomics Core Facility completed all RNA-seq library preparation and sequencing.

\section{$528 \quad$ RNA-seq analysis pipeline} Using Geneious Prime 2021.1.1 (https://www.geneious.com), sequence reads were trimmed using the BBDuk Trimmer prior to mapping to either the SK36 genome or a modified version, in which the $s s a A C B$ operon was replaced with the aphA-3 sequence. Original and new locus tags from the Genbank ${ }^{\circledR}$ annotations are included (Benson et al., 2013). PATRIC annotations (https://patricbrc.org/) (Wattam et al., 2017) are also included. Reads for each post-treatment sample were compared to the corresponding pre-treatment $\left(\mathrm{T}_{-20}\right)$ sample using DESeq2 (Love et $a l ., 2014)$ in Geneious to determine $\log _{2}$ fold changes and adjusted $P$-values. The same method was used to compare reads from WT to those from the $\triangle$ ssaACB mutant at each sample time point. Principal component analysis was completed using R (version 4.0.5) and RStudio (version 13.959) with Bioconductor (Bioconductor.com) package pcaExplorer version 2.160 (Marini \& Binder, 2019). Volcano plots were generated using R and RStudio with Bioconductor package EnhancedVolcano version 1.8.0 (Blighe et al., 2018). All DEGs were input into the DAVID database (https://david.ncifcrf.gov/summary.jsp) (Dennis et al., 2003). Since the new locus tags are not accepted in KEGG, only genes with original "SSA_" locus tags were included in the analysis. The KEGG_pathway option was chosen for functional annotation clustering. The $P$ value shows the significance of pathway enrichment. DAVID pathway figures were generated using an R script (https://github.com/DrBinZhu/DAVID FIG).

\section{Biofilm competition assays}

547 S. sanguinis pre-cultures (described above) were diluted 100-fold into $2 \mathrm{~mL}$ pre-warmed BM 548 (Loo et al., 2000) $+1 \%$ sucrose in 12 well plates. The cultures were grown for $24 \mathrm{~h}$ at $37^{\circ} \mathrm{C}$ aerobically $\left(\sim 21 \% \mathrm{O}_{2}\right)$. The media supernatant was carefully removed and discarded. Warm TY

550 (3\% tryptone, $0.1 \%$ yeast extract, $0.5 \% \mathrm{KOH}, 1 \mathrm{mM} \mathrm{H}_{3} \mathrm{PO}_{4}$ ) (Fozo \& Quivey, 2004) + 1\% sucrose was added to $2 \mathrm{~mL}$ and $S$. mutans + pVMTeal pre-cultures were diluted 100-fold into the wells. After $24 \mathrm{~h}$ incubation at $37^{\circ} \mathrm{C}, \mathrm{TY}+\mathrm{S}$ supernatant was carefully removed and the $\mathrm{pH}$ was measured. PBS was added to $1 \mathrm{~mL}$ and biofilms were scraped from each well. Each biofilm culture was sonicated for $90 \mathrm{~s}$ using an ultrasonic homogenizer. Cultures were diluted in PBS and plated on BHI plates with antibiotics using a spiral plater. Plates were incubated at $37^{\circ} \mathrm{C}$ for $24 \mathrm{~h}$ at $0 \% \mathrm{O}_{2}$. 


\section{Mouse model of oral colonization}

558 The mouse model was described in detail recently by Culp et al. (2020). Briefly, all procedures with solutions and samples were performed under BSL2 conditions and mice were kept under ABSL2 conditions. Inbred 3-week-old female SPF BALB/cJ mice (The Jackson Laboratory, Bar Harbor, ME) were placed in pairs in sterile cages. Two days later, mice were given drinking water containing $0.8 \mathrm{mg} / \mathrm{ml}$ sulphamethoxazole $/ 0.16 \mathrm{mg} / \mathrm{ml}$ trimethoprim for a total of 10 days to suppress indigenous oral bacteria, followed by a 3-day washout period with sterile drinking water. On the following day (designated experimental day 0) mice were placed on custom diet TD.160810 (Teklad, Madison, WI) containing 37.5\% sucrose and without fluoride, and inoculated daily over five days with $50 \mu \mathrm{l}$ of $1.5 \%$ (wt/vol) carboxymethylcellulose in saliva buffer $\left(50 \mathrm{mM} \mathrm{KCl}, 1.0 \mathrm{mM} \mathrm{KPO}, 0.35 \mathrm{mM} \mathrm{K} \mathrm{HPO}_{4}, 1.0 \mathrm{mM} \mathrm{CaCl} 22 \mathrm{H}_{2} \mathrm{O}, 0.1 \mathrm{mM} \mathrm{MgCl} 2\right.$ $6 \mathrm{H}_{2} \mathrm{O}$, pH 6.5) containing approximately $1 \times 10^{9}$ cells of the indicated strain grown to an $\mathrm{OD}_{600}$ between 0.55 to 0.70 in BHI. Two weeks later, mice received three daily inoculations with approximately $1 \times 10^{9}$ cells of $S$. mutans UA159. Mice were euthanized by $\mathrm{CO}_{2}$ asphyxiation followed by cervical dislocation. The protocol was approved by the Institutional Animal Care and Use Committee at University of Florida (IACUC protocol \#201810470). Oral swabs were taken using HydraFlock® 6" Sterile Micro Ultrafine Flock swabs (Puritan Medical Products, Guilford, ME). Swab tips were vortexed (3 times for $5 \mathrm{sec}$ ) in $1 \mathrm{ml}$ sterile PBS, the tips removed and $200 \mu \mathrm{l}$ added of ice-cold PBS containing approximately $5 \times 10^{8}$ depurinated cells of laboratory strain $S$. mitis UF2. Tubes were then vortexed $5 \mathrm{sec}$ and centrifuged $(10,000 \times g, 10$ min at $4{ }^{\circ} \mathrm{C}$ ) to pellet recovered cells. Cell pellets were then processed for DNA isolation using the DNeasy UltraClean Microbial kit (Qiagen Inc., Germantown, MD) as per manufacturer's instructions. Depurinated cells were devoid of detectable DNA by qPCR and allowed for quantitative recoveries of DNA from test strains and mouse commensals. To measure dental colonization, the left and right halves of each mandible were aseptically extracted and any remaining extraneous soft tissue removed followed by removal of bone approximately $2 \mathrm{~mm}$ anterior and posterior to the three molar teeth. Each pair of molars were sonicated on ice in $1 \mathrm{ml}$ sterile PBS, $\mathrm{pH} \mathrm{7.4,} \mathrm{in} \mathrm{siliconized} 2 \mathrm{ml}$ microcentrifuge tubes, the molars aseptically removed and approximately $5 \times 10^{8}$ depurinated cells of $S$. mitis UF2 then added, followed by vortexing for $5 \mathrm{sec}$ and centrifugation $\left(10,000 \times \mathrm{g}, 10 \mathrm{~min}\right.$ at $\left.4{ }^{\circ} \mathrm{C}\right)$. Cell pellets were then processed for DNA isolation as described for swabs. Recovered bacterial genomes in DNA samples were assessed by qPCR in $20 \mu \mathrm{l}$ reactions run in triplicate in a Bio-Rad CFX96 real-time PCR instrument using $10 \mu \mathrm{l}$ SsoAdvanced Universal SYBR®Green Supermix (Bio-Rad, Hercules, CA), $0.5 \mu$ l each primer and $9 \mu$ of DNA diluted in $4 \mathrm{mM}$ Tris-HCl, $\mathrm{pH}$ 8.0. Samples were run for $3 \mathrm{~min}$ at $98^{\circ} \mathrm{C}$ followed by either 34 cycles $(r p s L)$ or 40 cycles $\left(98^{\circ} \mathrm{C}, 15 \mathrm{~s}\right.$; annealing/elongation, $45 \mathrm{~s}$ at $70^{\circ} \mathrm{C}$ for $S$. mutans, $55^{\circ} \mathrm{C}$ for $r p s L$ and $64.5^{\circ} \mathrm{C}$ for $S$. sanguinis); followed by a melt curve from $65-95^{\circ} \mathrm{C}$ at $0.5^{\circ} \mathrm{C}$ increments. Primers were as follows: $S$. sanguinis (Forward, 5'-GAGCGAATCATCAAGGATCAAAC-3', Reverse, 5' CGAGCAATAGCTTT-CGTAATAGG-3'), S. mutans (Forward, 5'TGGCAAGTCCTGATGGTTTGAC-3', Reverse, 5'-GGAAGCGGAAGCTGTGATGAAC-3'), 597 rpsL (Forward, 5'-CCKAAYTCNGCNYTNCGT-AA-3', Reverse, 5'598 CGHACMCCWGGWARGTCYTT-3'). Primers were used at final concentrations of $0.50 \mu \mathrm{M}$ (S. mutans), $0.15 \mu \mathrm{M}$ (S. sanguinis) and $2.5 \mu \mathrm{M}$ (rpsL). Standard curves were derived from DNA samples isolated from each strain grown to mid-exponential phase in BHI. S. mutans UA159 was used as standard for $r p s L$ assays. Efficiencies, slopes and $r^{2}$ values for standard curves were greater than 90\%, -3.226 and 0.975, respectively. Results were analyzed using the Bio-Rad CFX 
603 Manager program. Under the listed conditions, all assays were specific for the targeted genomes.

604 All work was performed in a BioSafety cabinet under aseptic conditions.

\section{Data analysis and presentation}

606 Statistical tests were performed in GraphPad Prism 9.0 (graphpad.com) or R (Team, 2018).

607 Significance was determined by statistical tests indicated in the figure legends. $P$-values $\leq 0.05$

608 were considered significant. DESeq2 calculations of RNA-Seq datasets were completed in

609 Geneious Prime 2021.1 or in the pcaExplorer R package (Marini \& Binder, 2019). Confidence

610 intervals $(95 \%)$ of replicate samples were determined by the pcaExplorer $\mathrm{R}$ package.

\section{Acknowledgements}

612 We would like to thank Seon-Sook An, Karina Kunka, Shannon Green, and Jody Turner for their

613 advice and technical assistance.

\section{Author Contributions}

615 TP and TK designed the in vitro experiments and DJC and RAB designed the in vivo experiment. 616 TP completed the in vitro experiments and ACS, CAL and ASB completed the in vivo 617 experiment. TP, DJC, RAB, and TK wrote the manuscript. All authors reviewed and approved 618 the manuscript.

\section{Graphical Abstract}

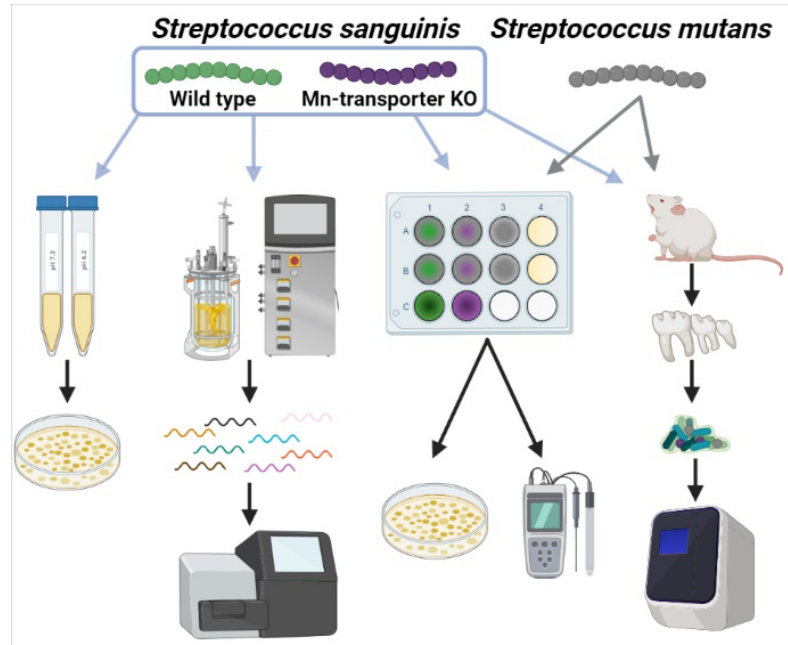

621 Depiction of methods. Streptococcal strains used are depicted at the top. The four methods illustrated are: 1 . S. sanguinis cells were grown in media at pH 7.3 and $\mathrm{pH} 6.2$ and quantified by plating. 2. S. sanguinis cells were grown in a fermentor vessel for RNA-sequencing and metal analysis. 3. S. sanguinis and $S$. mutans cells were grown in 12-well plates singly or in competition, then plated and the $\mathrm{pH}$ of the media measured. 4. $S$. sanguinis and $S$. mutans cells were inoculated into the mouths of mice. Oral swabs and dental biofilms from molars were assayed for bacterial composition by

628 qPCR. (Biorender)

\section{Abbreviated Summary}

630 Streptococcus sanguinis is an oral bacterium that competes with Streptococcus mutans, a 631 causative agent of dental caries. We report that growth of $S$. sanguinis SK36 in acidic media 
bioRxiv preprint doi: https://doi.org/10.1101/2021.05.28.446192; this version posted May 28, 2021. The copyright holder for this preprint (which

was not certified by peer review) is the author/funder, who has granted bioRxiv a license to display the preprint in perpetuity. It is made available under aCC-BY 4.0 International license.

632 leads to decreased manganese levels and changes in carbon catabolite repression. A knockout 633 mutant of the primary manganese transporter grows poorly in acidic media but shows similar 634 colonization and competition with $S$. mutans in vivo when compared to wild type. 


\section{References}

Aas, J.A., Paster, B.J., Stokes, L.N., Olsen, I., and Dewhirst, F.E. (2005) Defining the normal bacterial flora of the oral cavity. J. Clin. Microbiol. 43: 5721-5732.

Bai, Y., Shang, M., Xu, M., Wu, A., Sun, L., and Zheng, L. (2019) Transcriptome, phenotypic, and virulence analysis of Streptococcus sanguinis SK36 wild type and its CcpA-null derivative ( $\triangle \mathrm{CcpA})$. Front Cell Infect Microbiol 9: 411.

Baker, S.P., Nulton, T.J., and Kitten, T. (2019) Genomic, phenotypic, and virulence analysis of Streptococcus sanguinis oral and infective-endocarditis isolates. Infect. Immun. 87: e00703-00718.

Beighton, D. (1982) The influence of manganese on carbohydrate metabolism and caries induction by Streptococcus mutans strain Ingbritt. Caries Res. 16: 189-192.

Belda-Ferre, P., Alcaraz, L.D., Cabrera-Rubio, R., Romero, H., Simon-Soro, A., Pignatelli, M., and Mira, A. (2012) The oral metagenome in health and disease. ISME J 6: 46-56.

Bender, G.R., Sutton, S.V.W., and Marquis, R.E. (1986) Acid tolerance, proton permeabilities, and membrane ATPases of oral streptococci. Infect. Immun. 53: 331-338.

Benson, D.A., Cavanaugh, M., Clark, K., Karsch-Mizrachi, I., Lipman, D.J., Ostell, J., and Sayers, E.W. (2013) GenBank. Nucleic Acids Res. 41: D36-42.

Blighe, K., Rana, S., and Lewis, M., (2018) EnhancedVolcano: Publication-ready volcano plots with enhanced colouring and labeling. In. GitHub, pp.

Bor, D.H., Woolhandler, S., Nardin, R., Brusch, J., and Himmelstein, D.U. (2013) Infective endocarditis in the U.S., 1998-2009: a nationwide study. PLoS One 8: e60033.

Bruno-Barcena, J.M., Azcarate-Peril, M.A., and Hassan, H.M. (2010) Role of antioxidant enzymes in bacterial resistance to organic acids. Appl. Environ. Microbiol. 76: 27472753.

Burne, R.A., and Chen, Y.-Y.M. (1998) The use of continuous flow bioreactors to explore gene expression and physiology of suspended and adherent populations of oral streptococci. Methods Cell Sci. 20: 181-190.

Burne, R.A., Parsons, D.T., and Marquis, R.E. (1989) Cloning and expression in Escherichia coli of the genes of the arginine deiminase system of Streptococcus sanguis NCTC 10904. Infect. Immun. 57: 3540-3548.

Cahill, T.J., Baddour, L.M., Habib, G., Hoen, B., Salaun, E., Pettersson, G.B., Schafers, H.J., and Prendergast, B.D. (2017) Challenges in infective endocarditis. J. Am. Coll. Cardiol. 69: 325-344.

Caufield, P.W., Dasanayake, A.P., Li, Y., Pan, Y., Hsu, J., and Hardin, J.M. (2000) Natural history of Streptococcus sanguinis in the oral cavity of infants: evidence for a discrete window of infectivity. Infect. Immun. 68: 4018-4023.

Chen, T., Yu, W.H., Izard, J., Baranova, O.V., Lakshmanan, A., and Dewhirst, F.E. (2010) The Human Oral Microbiome Database: a web accessible resource for investigating oral microbe taxonomic and genomic information. Database (Oxford) 2010: baq013.

Chen, Y.Y., Shieh, H.R., and Chang, Y.C. (2013) The expression of the fim operon is crucial for the survival of Streptococcus parasanguinis FW213 within macrophages but not acid tolerance. PLoS One 8: e66163.

Cheng, X., Redanz, S., Cullin, N., Zhou, X., Xu, X., Joshi, V., Koley, D., Merritt, J., and Kreth, J. (2018) Plasticity of the pyruvate node modulates hydrogen peroxide production and acid tolerance in multiple oral streptococci. Appl. Environ. Microbiol. 84. 
Cotter, P.D., and Hill, C. (2003) Surviving the acid test: responses of gram-positive bacteria to low pH. Microbiol. Mol. Biol. Rev. 67: 429-453.

Crump, K.E., Bainbridge, B., Brusko, S., Turner, L.S., Ge, X., Stone, V., Xu, P., and Kitten, T. (2014) The relationship of the lipoprotein $\mathrm{SsaB}$, manganese and superoxide dismutase in Streptococcus sanguinis virulence for endocarditis. Mol. Microbiol. 92: 1243-1259.

Culp, D.J., Hull, W., Bremgartner, M.J., Atherly, T.A., Christian, K.N., Killeen, M., Dupuis, M.R., Schultz, A.C., Chakraborty, B., Lee, K., Wang, D.S., Afzal, V., Chen, T., and Burne, R.A. (2020) In vivo colonization with candidate oral probiotics attenuates colonization and virulence of Streptococcus mutans. Appl. Environ. Microbiol. 87.

Curran, T.M., Lieou, J., and Marquis, R.E. (1995) Arginine deiminase system and acid adaptation of oral streptococci. Appl. Environ. Microbiol. 61: 4494-4496.

Dennis, G., Jr., Sherman, B.T., Hosack, D.A., Yang, J., Gao, W., Lane, H.C., and Lempicki, R.A. (2003) DAVID: Database for Annotation, Visualization, and Integrated Discovery. Genome Biol 4: P3.

Diaz-Garrido, N., Lozano, C.P., Kreth, J., and Giacaman, R.A. (2020) Competition and caries on enamel of a dual-species biofilm model of Streptococcus mutans and Streptococcus sanguinis. Appl. Environ. Microbiol.

Djoko, K.Y., Phan, M.D., Peters, K.M., Walker, M.J., Schembri, M.A., and McEwan, A.G. (2017) Interplay between tolerance mechanisms to copper and acid stress in Escherichia coli. Proc Natl Acad Sci U S A 114: 6818-6823.

Dunning, D.W., McCall, L.W., Powell, W.F., Arscott, W.T., McConocha, E.M., McClurg, C.J., Goodman, S.D., and Spatafora, G.A. (2008) SloR modulation of the Streptococcus mutans acid tolerance response involves the GcrR response regulator as an essential intermediary. Microbiology 154: 1132-1143.

Edgar, R., Domrachev, M., and Lash, A.E. (2002) Gene Expression Omnibus: NCBI gene expression and hybridization array data repository. Nucleic Acids Res. 30: 207-210.

Floderus, E., Linder, L.E., and Sund, M.-L. (1990) Arginine catabolism by strains of oral streptococci. APMIS: Acta Pathol. Microbiol. Immunol. Scand. 98: 1045-1052.

Fozo, E.M., and Quivey, R.G., Jr. (2004) Shifts in the membrane fatty acid profile of Streptococcus mutans enhance survival in acidic environments. Appl. Environ. Microbiol. 70: 929-936.

Garcia-Mendoza, A., Liebana, J., Castillo, A.M., Higuera, A.d.l., and Piedrola, G. (1993) Evaluation of the capacity of oral streptococci to produce hydrogen peroxide. J. Med. Microbiol. 39: 434-439.

Giacaman, R.A., Torres, S., Gomez, Y., Munoz-Sandoval, C., and Kreth, J. (2015) Correlation of Streptococcus mutans and Streptococcus sanguinis colonization and ex vivo hydrogen peroxide production in carious lesion-free and high caries adults. Arch Oral Biol 60: 154159.

Gross, E.L., Beall, C.J., Kutsch, S.R., Firestone, N.D., Leys, E.J., and Griffen, A.L. (2012) Beyond Streptococcus mutans: Dental caries onset linked to multiple species by $16 \mathrm{~S}$ rRNA community analysis. PLoS One 7: e47722.

Guan, N., and Liu, L. (2020) Microbial response to acid stress: mechanisms and applications. Appl. Microbiol. Biotechnol. 104: 51-65.

Hamilton, I.R., and Svensäter, G. (1998) Acid-regulated proteins induced by Streptococcus mutans and other oral bacteria during acid shock. Oral Microbiol. Immunol. 13: 292-300. 
Jakubovics, N.S., (2015) Saliva as the sole nutritional source in the development of multispecies communities in dental plaque. In: Metabolism and Bacterial Pathogenesis. Washington, DC: American Society of Microbiology, pp. 263-277.

Jamil, M., Sultan, I., Gleason, T.G., Navid, F., Fallert, M.A., Suffoletto, M.S., and Kilic, A. (2019) Infective endocarditis: trends, surgical outcomes, and controversies. J Thorac Dis 11: 4875-4885.

Kajfasz, J.K., Katrak, C., Ganguly, T., Vargas, J., Wright, L., Peters, Z.T., Spatafora, G.A., Abranches, J., and Lemos, J.A. (2020) Manganese uptake, mediated by SloABC and $\mathrm{MntH}$, is essential for the fitness of Streptococcus mutans. mSphere 5: e00764-00719.

Kehres, D.G., Lawyer, C.H., and Maguire, M.E. (1998) The CorA magnesium transporter gene family. Microbial \& Comparative Genomics 3: 151-169.

Kim, J.S., Sung, M.H., Kho, D.H., and Lee, J.K. (2005) Induction of manganese-containing superoxide dismutase is required for acid tolerance in Vibrio vulnificus. J. Bacteriol. 187: 5984-5995.

Kindblom, C., Davies, J.R., Herzberg, M.C., Svensater, G., and Wickstrom, C. (2012) Salivary proteins promote proteolytic activity in Streptococcus mitis biovar 2 and Streptococcus mutans. Mol Oral Microbiol 27: 362-372.

Kitten, T., Munro, C.L., Zollar, N.Q., Lee, S.P., and Patel, R.D. (2012) Oral streptococcal bacteremia in hospitalized patients: taxonomic identification and clinical characterization. J. Clin. Microbiol. 50: 1039-1042.

Kolenbrander, P.E. (2011) Multispecies communities: interspecies interactions influence growth on saliva as sole nutritional source. Int J Oral Sci 3: 49-54.

Kolenbrander, P.E., Palmer, R.J., Jr., Periasamy, S., and Jakubovics, N.S. (2010) Oral multispecies biofilm development and the key role of cell-cell distance. Nat. Rev. Microbiol. 8: 471-480.

Kreth, J., Merritt, J., Shi, W., and Qi, F. (2005) Competition and coexistence between Streptococcus mutans and Streptococcus sanguinis in the dental biofilm. J. Bacteriol. 187: 7193-7203.

Kreth, J., Zhang, Y., and Herzberg, M.C. (2008) Streptococcal antagonism in oral biofilms: Streptococcus sanguinis and Streptococcus gordonii interference with Streptococcus mutans. J. Bacteriol. 190: 4632-4640.

Kuhnert, W.L., and Quivey, R.G., Jr. (2003) Genetic and biochemical characterization of the FATPase operon from Streptococcus sanguis 10904. J. Bacteriol. 185: 1525-1533.

Lamont, R.J., Koo, H., and Hajishengallis, G. (2018) The oral microbiota: dynamic communities and host interactions. Nat. Rev. Microbiol. 16: 745-759.

Lee, K., Walker, A.R., Chakraborty, B., Kaspar, J.R., Nascimento, M.M., and Burne, R.A. (2019) Novel probiotic mechanisms of the oral bacterium Streptococcus sp. A12 as explored with functional genomics. Appl. Environ. Microbiol. 85: e01335-01319.

Lemos, J.A., and Burne, R.A. (2002) Regulation and physiological significance of ClpC and ClpP in Streptococcus mutans. J. Bacteriol. 184: 6357-6366.

Lemos, J.A., Chen, Y.Y., and Burne, R.A. (2001) Genetic and physiologic analysis of the groE operon and role of the HrcA repressor in stress gene regulation and acid tolerance in Streptococcus mutans. J. Bacteriol. 183: 6074-6084.

Liu, Y., Tang, H., Lin, Z., and Xu, P. (2015) Mechanisms of acid tolerance in bacteria and prospects in biotechnology and bioremediation. Biotechnol. Adv. 33: 1484-1492. 
Loo, C.Y., Corliss, D.A., and Ganeshkumar, N. (2000) Streptococcus gordonii biofilm formation: identification of genes that code for biofilm phenotypes. J. Bacteriol. 182: 1374-1382.

Love, M.I., Huber, W., and Anders, S. (2014) Moderated estimation of fold change and dispersion for RNA-seq data with DESeq2. Genome Biol 15: 550.

Marini, F., and Binder, H. (2019) pcaExplorer: an R/Bioconductor package for interacting with RNA-seq principal components. BMC Bioinformatics 20: 1-8.

Marsh, P.D., Do, T., Beighton, D., and Devine, D.A. (2016) Influence of saliva on the oral microbiota. Periodontology 2000 70: 80-92.

Martin-Galiano, A.J., Overweg, K., Ferrandiz, M.J., Reuter, M., Wells, J.M., and de la Campa, A.G. (2005) Transcriptional analysis of the acid tolerance response in Streptococcus pneumoniae. Microbiology 151: 3935-3946.

Moye, Z.D., Zeng, L., and Burne, R.A. (2014) Fueling the caries process: carbohydrate metabolism and gene regulation by Streptococcus mutans. J Oral Microbiol 6.

Murgas, C.J., Green, S.P., Forney, A.K., Korba, R.M., An, S.S., Kitten, T., and Lucas, H.R. (2020) Intracellular metal speciation in Streptococcus sanguinis establishes SsaACB as critical for redox maintenance. ACS Infect Dis 6: 1906-1921.

Nascimento, M.M., Gordan, V.V., Garvan, C.W., Browngardt, C.M., and Burne, R.A. (2009) Correlations of oral bacterial arginine and urea catabolism with caries experience. Oral Microbiol. Immunol. 24: 89-95.

Nevo, Y., and Nelson, N. (2006) The NRAMP family of metal-ion transporters. Biochim. Biophys. Acta 1763: 609-620.

Papadimitriou, K., Alegria, A., Bron, P.A., de Angelis, M., Gobbetti, M., Kleerebezem, M., Lemos, J.A., Linares, D.M., Ross, P., Stanton, C., Turroni, F., van Sinderen, D., Varmanen, P., Ventura, M., Zuniga, M., Tsakalidou, E., and Kok, J. (2016) Stress physiology of lactic acid bacteria. Microbiol. Mol. Biol. Rev. 80: 837-890.

Puccio, T., and Kitten, T. (2020) Fermentor growth of Streptococcus sanguinis. protocols.io.

Puccio, T., Kunka, K.S., and Kitten, T. (2021a) Contribution of metal transporters of the ABC, ZIP, and NRAMP families to manganese uptake and infective endocarditis virulence in Streptococcus sanguinis. bioRxiv (accompanying manuscript).

Puccio, T., Kunka, K.S., Zhu, B., Xu, P., and Kitten, T. (2020) Manganese depletion leads to multisystem changes in the transcriptome of the opportunistic pathogen Streptococcus sanguinis. Front Microbiol 11: 592615.

Puccio, T., Misra, B.B., and Kitten, T. (2021b) Time-course analysis of Streptococcus sanguinis after manganese depletion reveals changes in glycolytic and nucleic metabolites. Metabolomics 17: 44.

Puccio, T., Schultz, A.C., Lizarraga, C.A., Bryant, A.S., Culp, D.J., Burne, R.A., and Kitten, T., (2021c) [dataset] Manganese transport by Streptococcus sanguinis in acidic conditions and its impact on growth in vitro and in vivo. Data available upon request.

Quivey, R.G., Kuhnert, W.L., and Hahn, K. (2001) Genetics of acid adaptation in oral streptococci. Crit. Rev. Oral Biol. Medicine 12: 301-314.

Radin, J.N., Kelliher, J.L., Parraga Solorzano, P.K., and Kehl-Fie, T.E. (2016) The twocomponent system ArlRS and alterations in metabolism enable Staphylococcus aureus to resist calprotectin-induced manganese starvation. PLoS Pathog 12: e1006040. 
Rhodes, D.V., Crump, K.E., Makhlynets, O., Snyder, M., Ge, X., Xu, P., Stubbe, J., and Kitten, T. (2014) Genetic characterization and role in virulence of the ribonucleotide reductases of Streptococcus sanguinis. J. Biol. Chem. 289: 6273-6287.

Santi, I., Grifantini, R., Jiang, S.-M., Brettoni, C., Grandi, G., Wessels, M.R., and Soriani, M. (2009) CsrRS regulates group B Streptococcus virulence gene expression in response to environmental pH: a new perspective on vaccine development. J. Bacteriol. 191: 53875397.

Sasaki, M., Kodama, Y., Shimoyama, Y., Ishikawa, T., and Kimura, S. (2018) Aciduricity and acid tolerance mechanisms of Streptococcus anginosus. J. Gen. Appl. Microbiol. 64: 174179.

Senouci-Rezkallah, K., Schmitt, P., and Jobin, M.P. (2011) Amino acids improve acid tolerance and internal pH maintenance in Bacillus cereus ATCC14579 strain. Food Microbiol. 28: 364-372.

Shabayek, S., Bauer, R., Mauerer, S., Mizaikoff, B., and Spellerberg, B. (2016) A streptococcal NRAMP homologue is crucial for the survival of Streptococcus agalactiae under low $\mathrm{pH}$ conditions. Mol. Microbiol. 100: 589-606.

Shabayek, S., and Spellerberg, B. (2017) Acid stress response mechanisms of group B streptococci. Front Cell Infect Microbiol 7: 395.

Svensater, G., Larsson, U.-B., Greif, E.C.G., Cvitkovitch, D.G., and Hamilton, I.R. (1997) Acid tolerance response and survival by oral bacteria. Oral Microbiol. Immunol. 12: 266-273.

Taudte, N., and Grass, G. (2010) Point mutations change specificity and kinetics of metal uptake by ZupT from Escherichia coli. BioMetals 23: 643-656.

Team, R.C. (2018) R: A language and environment for statistical computing.

Turner, L.S., Das, S., Kanamoto, T., Munro, C.L., and Kitten, T. (2009) Development of genetic tools for in vivo virulence analysis of Streptococcus sanguinis. Microbiology 155: 25732582.

Vickerman, M.M., Mansfield, J.M., Zhu, M., Walters, K.S., and Banas, J.A. (2015) Codonoptimized fluorescent mTFP and mCherry for microscopic visualization and genetic counterselection of streptococci and enterococci. J. Microbiol. Methods 116: 15-22.

Wattam, A.R., Davis, J.J., Assaf, R., Boisvert, S., Brettin, T., Bun, C., Conrad, N., Dietrich, E.M., Disz, T., Gabbard, J.L., Gerdes, S., Henry, C.S., Kenyon, R.W., Machi, D., Mao, C., Nordberg, E.K., Olsen, G.J., Murphy-Olson, D.E., Olson, R., Overbeek, R., Parrello, B., Pusch, G.D., Shukla, M., Vonstein, V., Warren, A., Xia, F., Yoo, H., and Stevens, R.L. (2017) Improvements to PATRIC, the all-bacterial bioinformatics database and analysis resource center. Nucleic Acids Res. 45: D535-D542.

Wen, Z.T., and Burne, R.A. (2004) LuxS-mediated signaling in Streptococcus mutans is involved in regulation of acid and oxidative stress tolerance and biofilm formation. $J$. Bacteriol. 186: 2682-2691.

Wickström, C., Chávez de Paz, L., Davies, J.R., and Svensäter, G. (2013) Surface-associated MUC5B mucins promote protease activity in Lactobacillus fermentum biofilms. BMC Oral Health 13: 43.

Wilson, W.R., Gewitz, M., Lockhart, P.B., Bolger, A.F., DeSimone, D.C., Kazi, D.S., Couper, D.J., Beaton, A., Kilmartin, C., Miro, J.M., Sable, C., Jackson, M.A., and Baddour, L.M. (2021) Prevention of viridans group streptococcal infective endocarditis: A scientific statement from the American Heart Association. Circulation 143: e1-16. 
Xu, P., Alves, J.M., Kitten, T., Brown, A., Chen, Z., Ozaki, L.S., Manque, P., Ge, X., Serrano, M.G., Puiu, D., Hendricks, S., Wang, Y., Chaplin, M.D., Akan, D., Paik, S., Peterson, D.L., Macrina, F.L., and Buck, G.A. (2007) Genome of the opportunistic pathogen Streptococcus sanguinis. J. Bacteriol. 189: 3166-3175.

$\mathrm{Xu}$, Y., Itzek, A., and Kreth, J. (2014) Comparison of genes required for $\mathrm{H}_{2} \mathrm{O}_{2}$ resistance in Streptococcus gordonii and Streptococcus sanguinis. Microbiology 160: 2627-2638.

Zhu, B., Ge, X., Stone, V., Kong, X., El-Rami, F., Liu, Y., Kitten, T., and Xu, P. (2017) ciaR impacts biofilm formation by regulating an arginine biosynthesis pathway in Streptococcus sanguinis SK36. Sci Rep 7: 17183.

Tables

Table 1. Strains and plasmids used in this study

\begin{tabular}{|c|c|c|}
\hline Strain & Description & Source or Reference \\
\hline SK36 & Human oral plaque isolate & $\begin{array}{l}\text { Mogens Killan (Aarhus } \\
\text { University); } \\
\text { Xu et al. (2007) }\end{array}$ \\
\hline JFP56 & $\triangle$ SSA_0169::aad9, derived from SK36 & Turner et al. (2009) \\
\hline JFP169 ${ }^{\dagger}$ & $\triangle s s a A C B:: a p h A-3$, derived from SK36 & Baker et al. (2019) \\
\hline JFP173 & $\triangle s s a A C B:: t e t M$, derived from SK36 & Baker et al. (2019) \\
\hline JFP226 & $\triangle t m p A:: a p h A-3$, derived from SK36 & Puccio et al. (2021a) \\
\hline JFP227 & $\begin{array}{l}\triangle \text { ssaACB::tetM } \triangle \text { tmpA::aphA-3, unintentional mutation: } \\
\text { SSA_1414-W139*; derived from SK36 }\end{array}$ & Puccio et al. (2021a) \\
\hline JFP377 & $\begin{array}{l}\triangle s s a A C B:: t e t M \triangle t m p A:: a p h A-3 \text {, clean version, derived from } \\
\text { SK36 }\end{array}$ & Puccio et al. (2021a) \\
\hline VMC66 & Human endocarditis isolate & Kitten et al. (2012) \\
\hline JFP313 & $\triangle s s a A C B:: a p h A-3$, derived from VMC66 & Puccio et al. (2021a) \\
\hline JFP317 & $\triangle t m p A:: p S e r m$, derived from VMC66 & Puccio et al. (2021a) \\
\hline JFP320 & $\triangle s s a A C B:: a p h A-3 \triangle t m p A:: p S e r m$, derived from VMC66 & Puccio et al. (2021a) \\
\hline JFP367 & $\Delta m n t H:: t e t M$, derived from VMC66 & Puccio et al. (2021a) \\
\hline JFP370 & $\triangle s s a A C B:: c a t \triangle m n t H:: t e t M$, derived from VMC66 & Puccio et al. (2021a) \\
\hline UA159 & Wild type $S$. mutans & ATCC 700610 \\
\hline Plasmid & Description & References \\
\hline pVMTeal & Plasmid encoding Erm ${ }^{\mathrm{R}}$ for use in S. mutans & $\begin{array}{l}\text { Vickerman et al. (2015) } \\
\text { Zhu et al. (2017) }\end{array}$ \\
\hline
\end{tabular}

$871{ }^{\dagger}$ Designated $\triangle s s a A C B$ throughout the manuscript.

$872 \ddagger$ Used only for growth studies and metal analysis in Figures 2, 3, and S1.

$873{ }^{\S}$ Used only for metal analysis in Figure 3A.

\section{Figure Legends}

875 Figure 1. Growth of the $S$. sanguinis SK36 WT and an $\triangle s s a A C B$ mutant in reduced-pH 876 BHI

$877 \mathrm{BHI}$ at different $\mathrm{pH}$ levels was preincubated at $1 \% \mathrm{O}_{2}$ and inoculated from an overnight culture. 878 Cultures were incubated for $24 \mathrm{~h}$ prior to plating. (A) Growth in BHI at various $\mathrm{pH}$ levels was 
assessed. (B) Exogenous $\mathrm{Mn}^{2+}$ was added at listed concentrations. Means and standard deviations of at least three replicates are displayed. Significance was determined by unpaired two-tailed t-tests for $\mathrm{T}_{0}$ values and one-way ANOVA with a Tukey multiple comparisons posttest for $\mathrm{T}_{24}$ values. Bars with the same letter are not significantly different from each other $(P>$

883 0.05).

884 Figure 2. Effect of the loss of manganese transporters on growth of S. sanguinis SK36 and 885 VMC66 strains in reduced-pH BHI

886 Growth of manganese transporter mutants in the SK36 (A) and VMC66 (B) backgrounds was assessed in $\mathrm{BHI}$ at $\mathrm{pH} 7.3$ and $\mathrm{pH} 6.2$ in $1 \% \mathrm{O}_{2}$. Strains that grew poorly in A \& B were assessed for growth under the same conditions \pm various concentrations of $\mathrm{Mn}^{2+}(\mathrm{C}-\mathrm{D})$. Means and standard deviations of at least three replicates are displayed. Significance was determined by one-way ANOVA with a Tukey multiple comparisons post-test separately for $\mathrm{T}_{0}$ and $\mathrm{T}_{24}$ values (vertical dashed lines). Bars with the same letter within a chart are not significantly different $(P>$ 0.05). Bars with $\delta$ indicate that at least one replicate fell below the limit of detection.

893 Figure 3. Manganese content of S. sanguinis SK36 and VMC66 and their respective manganese transporter mutants

895 Manganese content of transporter mutants in the SK36 (A \& B) and VMC66 (C \& D) backgrounds in $\mathrm{BHI} \pm 10 \mu \mathrm{M} \mathrm{Mn}^{2+}$ at $\mathrm{pH} 7.3$ (A-C) and pH 6.2 (B-D) was assessed by ICP-OES. Means and standard deviations of at least three replicates are displayed. Significance was determined by one-way ANOVA with Bonferonni's multiple comparisons tests comparing each mutant strain to its respective parent under the same growth conditions. Bars indicated by $\delta$ had at least one value that fell below the lowest standard. Data used in A \& B are also included in the accompanying paper (Puccio et al., 2021a).

Figure 4. Metal content of fermentor-grown S. sanguinis SK36 WT and $\triangle$ ssaACB mutant cells before and after $\mathrm{pH}$ reduction

904 Fermentor-grown (A) WT and (B) $\triangle s s a A C B$ cells were collected at each time point and analyzed for cellular metal content using ICP-OES. Metal concentrations were normalized to protein concentrations. Means and standard deviations of at least three replicates are displayed. Significance was determined by one-way ANOVA with Dunnett's multiple comparisons tests

909 Figure 5. Pathway enrichment analysis of the transcriptome of fermentor-grown $S$. 910 sanguinis SK36 WT and $\triangle s s a A C B$ mutant cells after pH reduction

911 (A) Tallies of DEGs, which are defined as $P \leq 0.05$ and $\mid \log _{2}$ fold change $\mid \geq 1$. Values in blue 912 indicate the number of genes downregulated at that time point relative to $\mathrm{T}_{-20}$; red values indicate 913 those that were upregulated. Green values indicate the number of genes that were more highly 914 expressed in WT and purple values indicate the number of genes that were more highly 915 expressed in the $\triangle s s a A C B$ mutant. Pathway enrichment analysis using DAVID functional 916 classification with KEGG annotations of DEGs at $\mathrm{T}_{50}$ compared to $\mathrm{T}_{-20}$ for (B) WT and (C) $917 \triangle \operatorname{ssaACB}$ strains. 
920 S. sanguinis cultures were grown aerobically for $24 \mathrm{~h}$ in $\mathrm{BM}+\mathrm{S}$. Media was swapped for TY+S and $S$. mutans was inoculated. Cultures were incubated an additional $24 \mathrm{~h}$ before media was removed and cells scraped from wells were resuspended in PBS for plating on BHI agar plates with antibiotics for selection. Means and standard deviations of $S$. mutans (A) and S. sanguinis (B) $\mathrm{CFU} \mathrm{mL} \mathrm{m}^{-1}$ from three biological replicates with two technical replicates each are shown. The $\delta$ indicates that 5 of 6 replicates fell below the limit of detection. (C) Means and standard deviation of media $\mathrm{pH}$ measurements for each culture are shown. Statistical analysis was performed using one-way ANOVA with a Tukey multiple comparisons post-test. Bars with the same letter within a chart are not significantly different $(P>0.05)$.

929 Figure 7. Comparison of oral colonization by $S$. sanguinis SK36 WT and $\triangle$ ssaACB strains, and in subsequent competition with $S$. mutans UA159 in vivo

931 (A) Timeline of key events in the experiment. (B) Colonization results for each indicated $S$. sanguinis strain (closed triangles, solid lines), S. mutans UA159 (open circles, dashed lines) and mouse oral commensals (closed squares, dotted lines) from oral swabs 1-5 taken at the times indicated in A and from sonicates of mandibular molars. S. sanguinis SK36 WT is depicted in green (left) and the $\triangle s s a A C B$ mutant is depicted in purple (right). Means and standard error $(\mathrm{n}=$ 12 mice per cohort) of recovered genomes estimated by qPCR are shown. Significant differences within each bacterial species/group between the two cohorts of mice were calculated using oneway ANOVA with Bonferroni's multiple comparisons tests for each sample time point $(* P<$ 0.05 , ** $P<0.01)$. Mice were fed a high-sucrose powdered diet with sterile drinking water.

940 Figure 8. Summary of the role of manganese transporters in the growth of S. sanguinis in reduced-pH conditions

942 Diagrams of $S$. sanguinis WT (A) SK36 and (B) VMC66 strains at pH 7.3 (left) and pH 6.2

943 (right) with their known manganese transporters depicted. In both WT cells (top), all transporters

944 are present so although TmpA function is reduced, manganese is acquired in sufficient levels to

945 support growth. In SK36 $\triangle s s a A C B$ mutant cells (bottom), TmpA is capable of transporting 946 enough manganese at $\mathrm{pH} 7.4$ to support the fast growth rate of cells in the fermentor; however, at pH 6.2, TmpA-mediated manganese transport is insufficient to maintain growth in the fermentor or in tube cultures. In VMC66 $\triangle s s a A C B$ mutant cells (bottom), MntH is able to compensate for the reduced function of TmpA at $\mathrm{pH}$ 6.2, resulting in sufficient manganese levels to support

950 growth. Either TmpA or MntH can provide sufficient manganese to support growth at $\mathrm{pH} 7.3$ in

951 the absence of the other two transporters; this is also true at $\mathrm{pH} 6.2$ for MntH but not for TmpA.

\section{Supporting Information}

953 Puccio_et_al_Supp_Tables.xlsx Excel document Supplementary Tables

954 Puccio_et_al_Suppinfo.pdf PDF document Supplementary Figures 


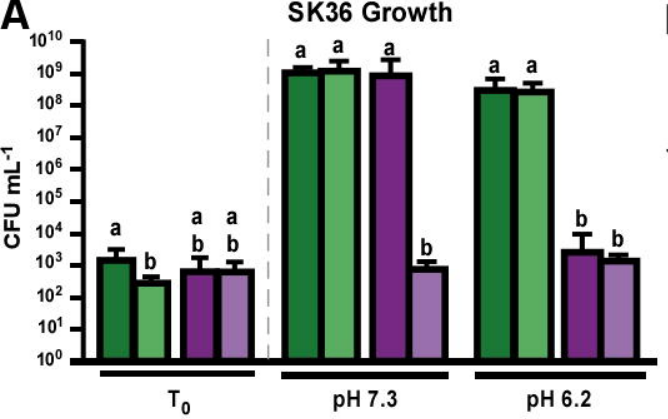

$B_{10}$

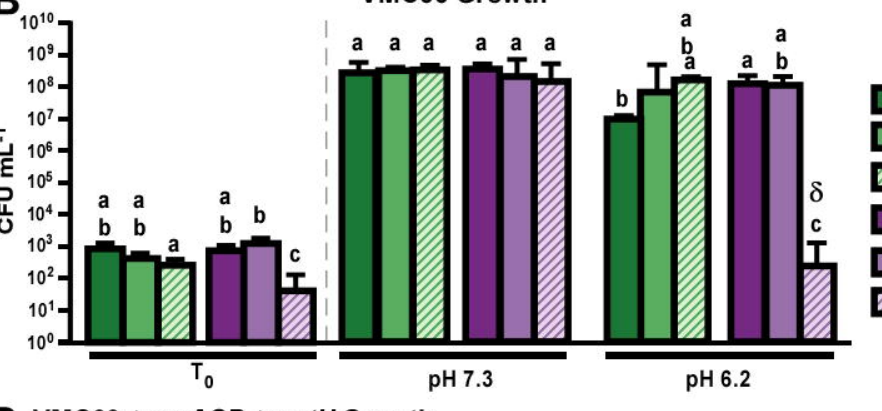

D VMC66 $\Delta s s a A C B \Delta m n t H$ Growth
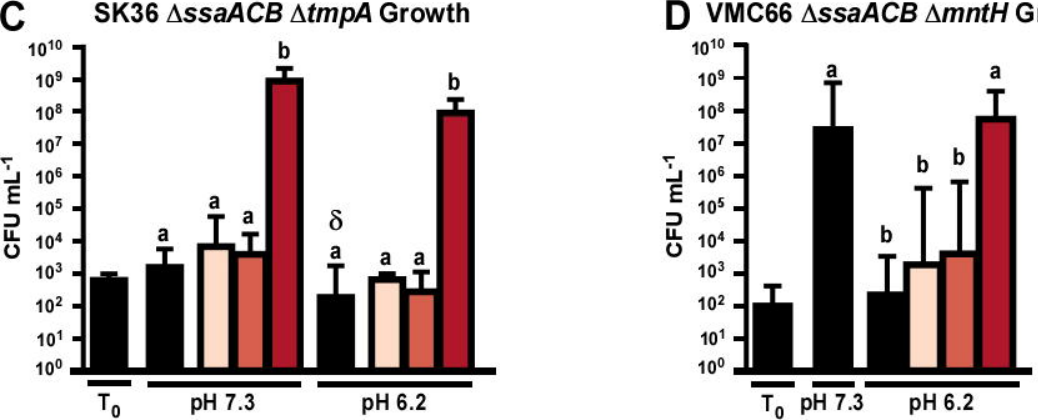

Condition

$+0 \mu \mathrm{M} \mathrm{Mn}^{2+}$

口 $+0.1 \mu \mathrm{M} \mathrm{Mn}^{2+}$

口 $+1 \mu \mathrm{M} \mathrm{Mn}^{2+}$

口+ $10 \mu \mathrm{M} \mathrm{Mn}^{2+}$
Genotype

$\square$ Wild type

口 $\triangle t m p A$

- $\triangle m n t H$

$\triangle{ }_{\triangle S s} A C B$

$\triangle s s a A C B \triangle t m p A$

$\nabla \Delta s s a A C B \triangle m n t H$ 
A

SK36 Mn Content at pH 7.3

WT Parent

$\triangle s s a A C B$ Parent

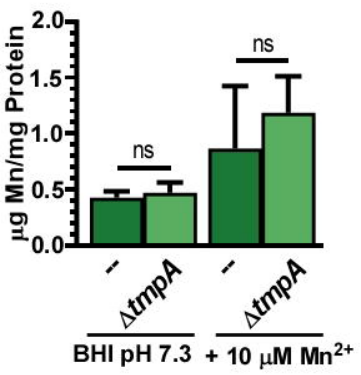

SK36 Mn Content at pH 6.2 WT Parent

$\triangle s s a A C B$ Parent

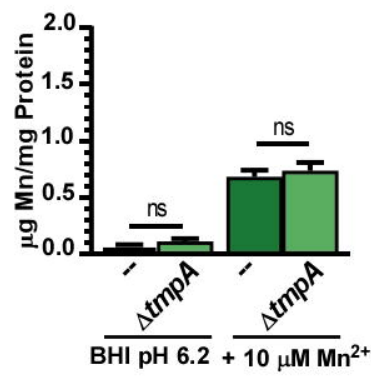

C

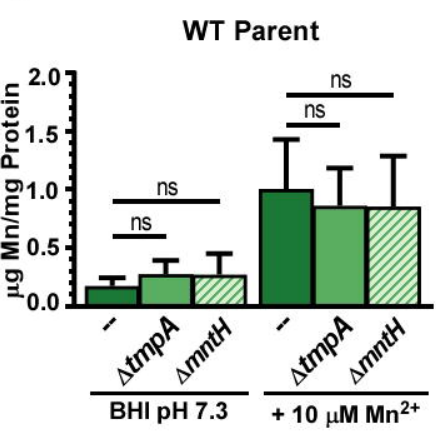

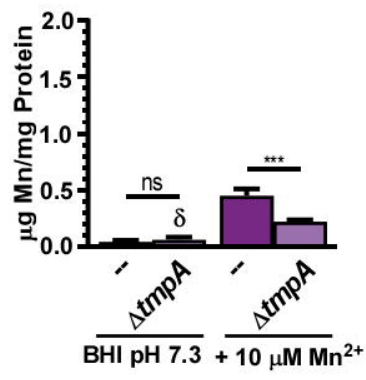

D

\section{VMC66 Mn Content at pH 6.2}

WT Parent

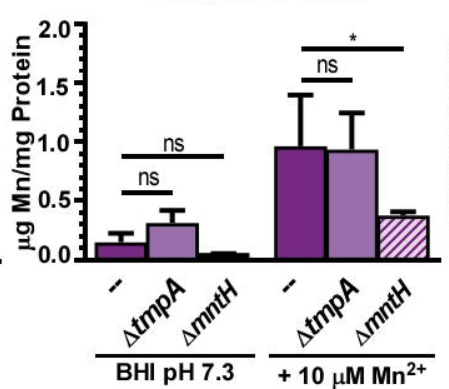

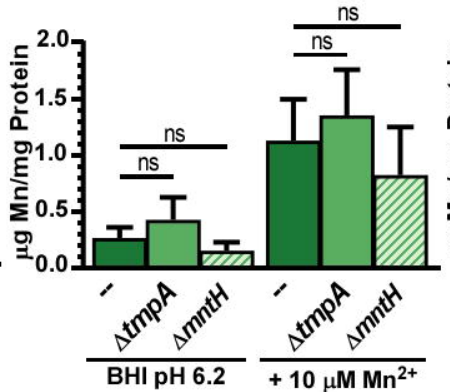

$\triangle$ ssaACB Parent

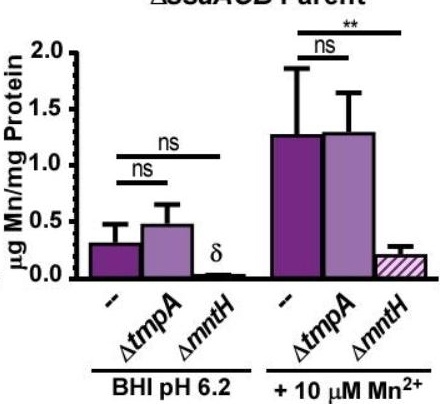



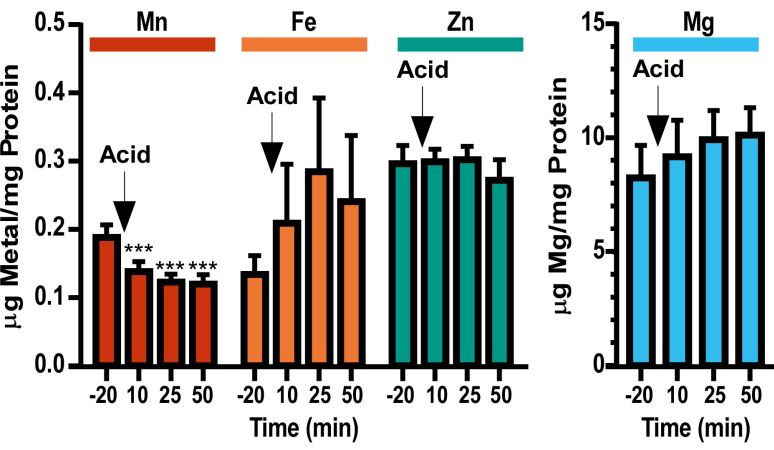

\section{$\triangle$ ssaACB}

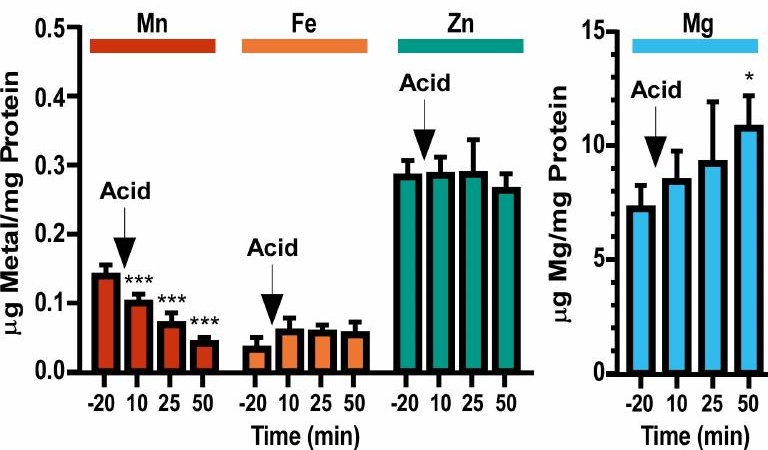




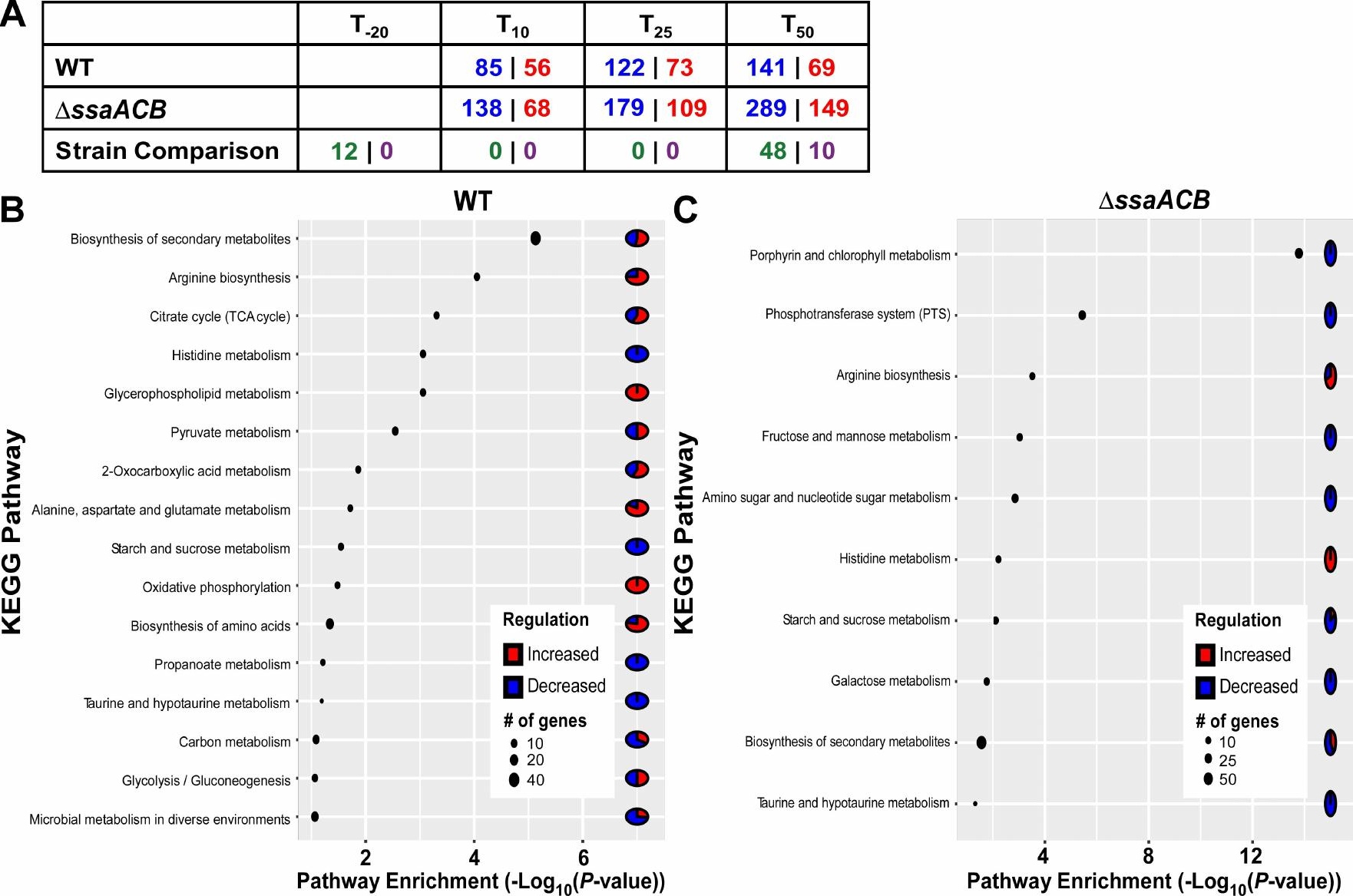


S. mutans Growth B $\quad$ S. sanguinis Growth

pH of TY+S Supernatant
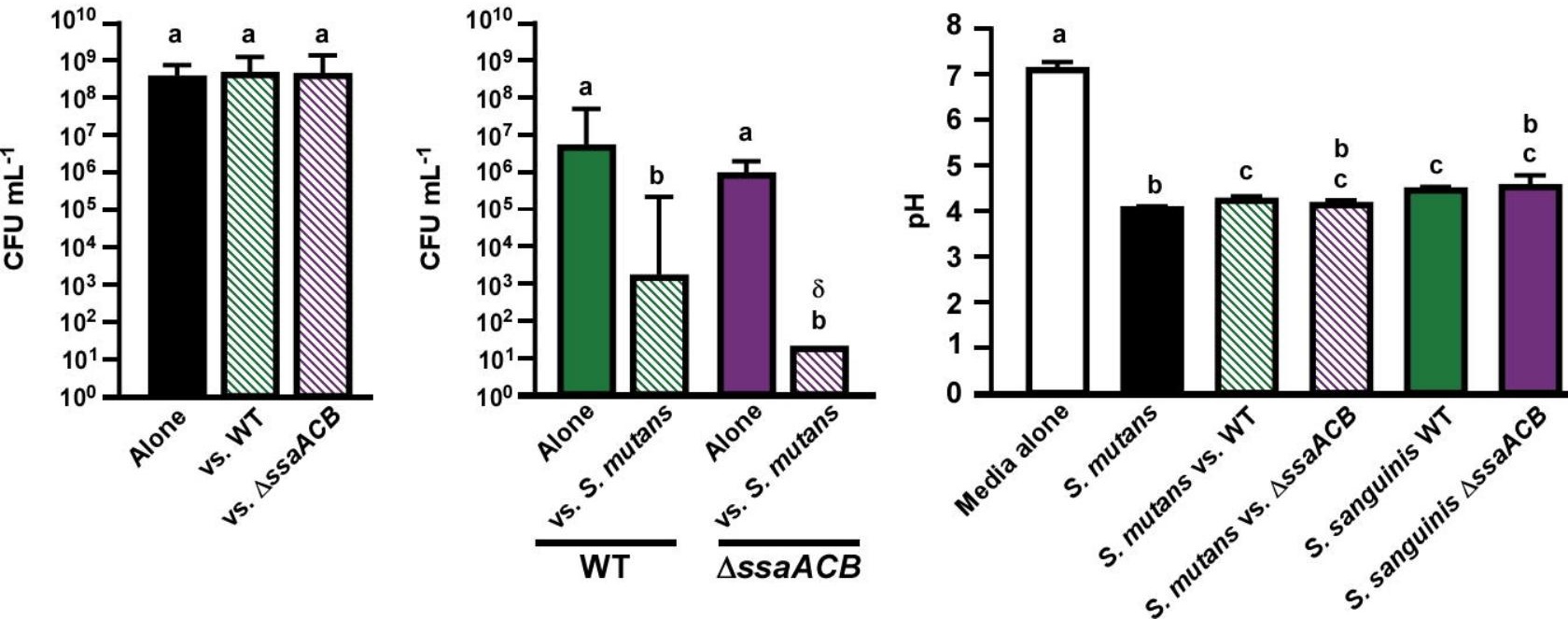

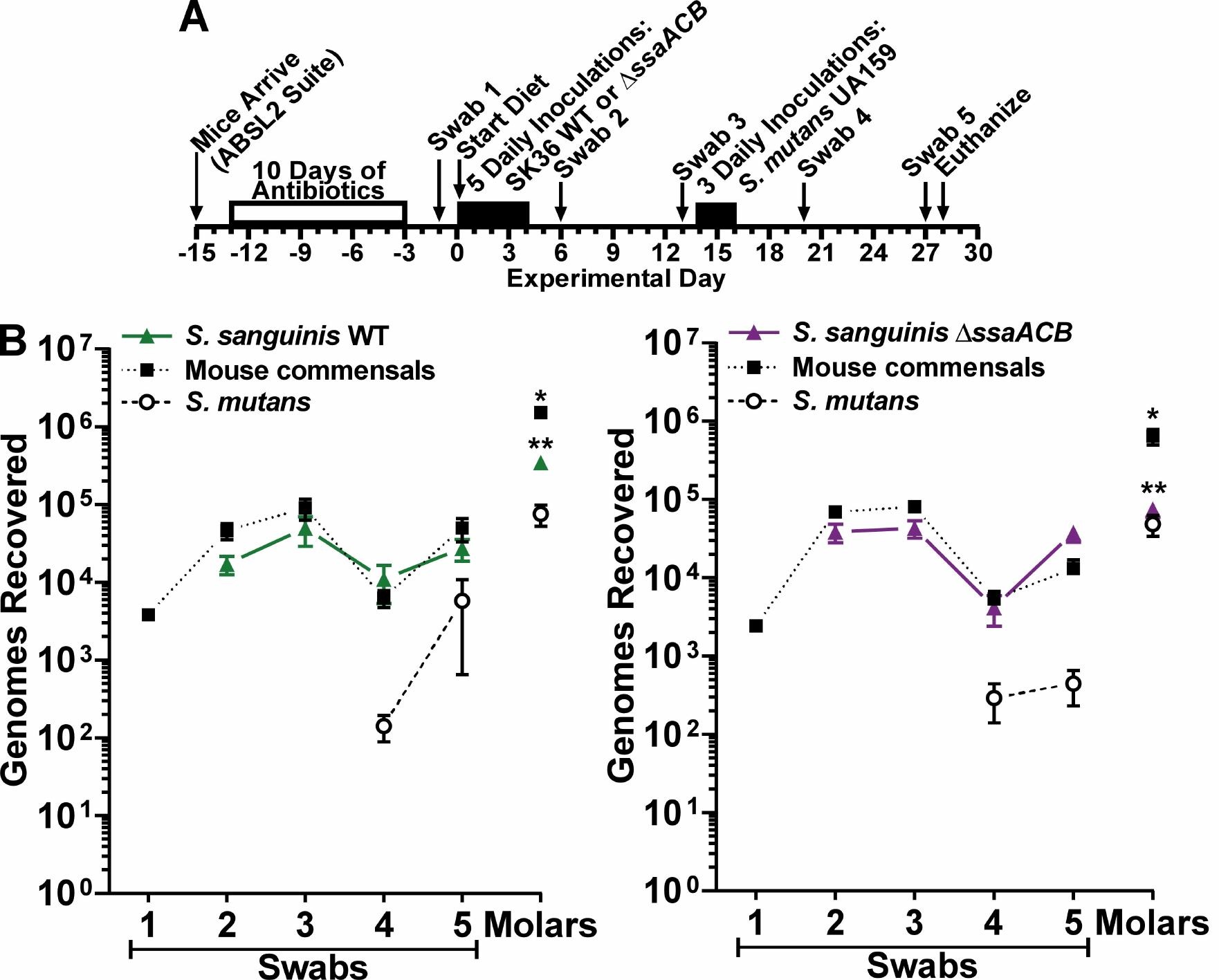
SK36

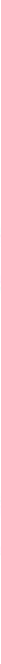

VMC66 